ARTICLE

\title{
Chemical proteomic profiling reveals protein interactors of the alarmones diadenosine triphosphate and tetraphosphate
}

\author{
Lena Krüger ${ }^{1,2,4}$, Christoph J. Albrecht ${ }^{1,2,4}$, Hannah K. Schammann ${ }^{1}$, Florian M. Stumpf ${ }^{1,2}$,
} Marie L. Niedermeier ${ }^{2,3}$, Yizhi Yuan ${ }^{1,2}$, Katrin Stuber ${ }^{1,2,3}$, Josua Wimmer ${ }^{1}$, Florian Stengel ${ }^{2,3}$, Martin Scheffner (iD) ${ }^{2,3} \&$ Andreas Marx (iD) ${ }^{1,2}{ }^{凶}$

The nucleotides diadenosine triphosphate $\left(A p_{3} A\right)$ and diadenosine tetraphosphate $\left(A p_{4} A\right)$ are formed in prokaryotic and eukaryotic cells. Since their concentrations increase significantly upon cellular stress, they are considered to be alarmones triggering stress adaptive processes. However, their cellular roles remain elusive. To elucidate the proteome-wide interactome of $A_{3} A$ and $A p_{4} A$ and thereby gain insights into their cellular roles, we herein report the development of photoaffinity-labeling probes and their employment in chemical proteomics. We demonstrate that the identified $\mathrm{Ap}_{n} \mathrm{~A}$ interactors are involved in many fundamental cellular processes including carboxylic acid and nucleotide metabolism, gene expression, various regulatory processes and cellular response mechanisms and only around half of them are known nucleotide interactors. Our results highlight common functions of these $A p_{n} A s$ across the domains of life, but also identify those that are different for $A p_{3} A$ or $A p_{4} A$. This study provides a rich source for further functional studies of these nucleotides and depicts useful tools for characterization of their regulatory mechanisms in cells.

\footnotetext{
${ }^{1}$ Department of Chemistry, University of Konstanz, Konstanz, Germany. ${ }^{2}$ Konstanz Research School-Chemical Biology, University of Konstanz, Konstanz, Germany. ${ }^{3}$ Department of Biology, University of Konstanz, Konstanz, Germany. ${ }^{4}$ These authors contributed equally: Lena Krüger, Christoph J. Albrecht. ${ }_{\text {email: andreas.marx@uni-konstanz.de }}$
} 
$\mathrm{D}$ inucleoside polyphosphates $\left(\mathrm{Np}_{n} \mathrm{Ns}\right)$ are a family of nucleotides which were discovered in bacteria and eukaryotic cells already in the $1960 \mathrm{~s}^{1}$, but their cellular roles and functions remain mostly elusive. The most widely studied family members are diadenosine polyphosphates $\left(\mathrm{Ap}_{n} \mathrm{As}\right)$, like diadenosine triphosphate $\mathrm{Ap}_{3} \mathrm{~A}$ and diadenosine tetraphosphate $\mathrm{Ap}_{4} \mathrm{~A}^{2,3}$. As their cellular concentrations increase in response to extracellular cues such as $\mathrm{pH}$, temperature and oxidative stress from a nanomolar to a lower micromolar range, $A p_{n}$ As have been considered to be alarmones that signal cellular stress $^{2,4,5}$. However, the underlying mechanisms and pathways remain to be elucidated.

It is assumed that the main source of intracellular $A p_{n} A s$ is a side reaction of aminoacyl-tRNA synthetases $(\mathrm{aaRSs})^{6}$, since several studies have shown that across species aaRSs can produce $A p_{n}$ As. Recently, it was reported that activation of the posttranslational modifiers ubiquitin and ubiquitin-like proteins (i.e., SUMO, NEDD8) is accompanied by the formation of $\mathrm{Ap}_{4} \mathrm{~A}$ and $\mathrm{Ap}_{3} \mathrm{~A}$ linking one of the most prevalent eukaryotic protein modification systems to $A p_{n} A$ formation ${ }^{7}$.

In higher eukaryotes, two proteins have been identified that are responsible for the degradation of $\mathrm{Ap}_{3} \mathrm{~A}$ and $\mathrm{Ap}_{4} \mathrm{~A}$. In humans, $\mathrm{Ap}_{3} \mathrm{~A}$ is cleaved into AMP and ADP by the tumor suppressor protein fragile histidine triad (FHIT) ${ }^{8}$, whereas Nudix (nucleoside diphosphate linked to X) type motif 2 (NUDT2) hydrolyzes $\mathrm{Ap}_{4} \mathrm{~A}$ to AMP and ATP ${ }^{9}$. The malfunction of these enzymes results in severe consequences for the affected cells or organisms. Dysfunction or absence of FHIT are frequently observed in various types of cancer ${ }^{10}$. NUDT2 has been proposed as a prognostic marker for breast and lung carcinoma, due to its enhanced activity in these carcinogenic tissues ${ }^{11}$. The absence of NUDT2, on the other hand, causes downregulation of the immune response ${ }^{12}$.

In this work, we report the development and chemoproteomic evaluation of $\mathrm{Ap}_{n} \mathrm{~A}$-based photoaffinity-labeling probes (PALPs) (Fig. 1) to elucidate the interactome of $A_{3} \mathrm{~A}$ and $\mathrm{Ap}_{4} \mathrm{~A}$ and eventually gain insights into their intracellular roles. These PALPs are equipped with diazirine (DA) as photoreactive group, enabling the formation of a covalent bond between the probe and an interacting protein upon UV irradiation, and desthiobiotin (DTB) as affinity tag. By applying these PALPs in photoaffinity enrichment assays followed by LC-MS/MS (Fig. 1a), we identified 61 significantly enriched proteins for $\mathrm{Ap}_{3} \mathrm{~A}$ and 26 for $\mathrm{Ap}_{4} \mathrm{~A}$ from human embryonic kidney (HEK293T) cell lysates. Interestingly, while nine proteins were identified with both $\mathrm{Ap}_{n} \mathrm{~A}$ baits, 52 proteins were exclusively found for $\mathrm{Ap}_{3} \mathrm{~A}$ and 17 for $\mathrm{Ap}_{4} \mathrm{~A}$, respectively. Gene ontology (GO) analysis reveals the involvement of these potential $\mathrm{Ap}_{\mathrm{n}} \mathrm{A}$ interactors in different fundamental cellular processes including carboxylic acid and nucleotide metabolism, gene expression, and various regulatory processes. In addition, we used our PALPs to probe for interactors in E. coli cells and identified overall 20 significantly enriched proteins. These proteins are also mainly associated with metabolism highlighting a common role of these $\mathrm{Ap}_{\mathrm{n}} \mathrm{As}$ across the domains of life. Moreover, only about half of the identified proteins are known nucleotide binders which indicates roles of $\mathrm{Ap}_{3} \mathrm{~A}$ and $\mathrm{Ap}_{4} \mathrm{~A}$ in cellular pathways that are distinguishable from those of other nucleotides. Taken together, this study demonstrates the power of our

a
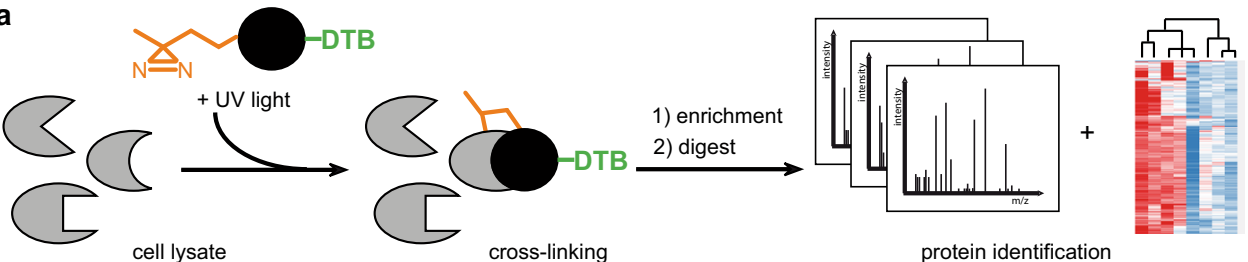

b
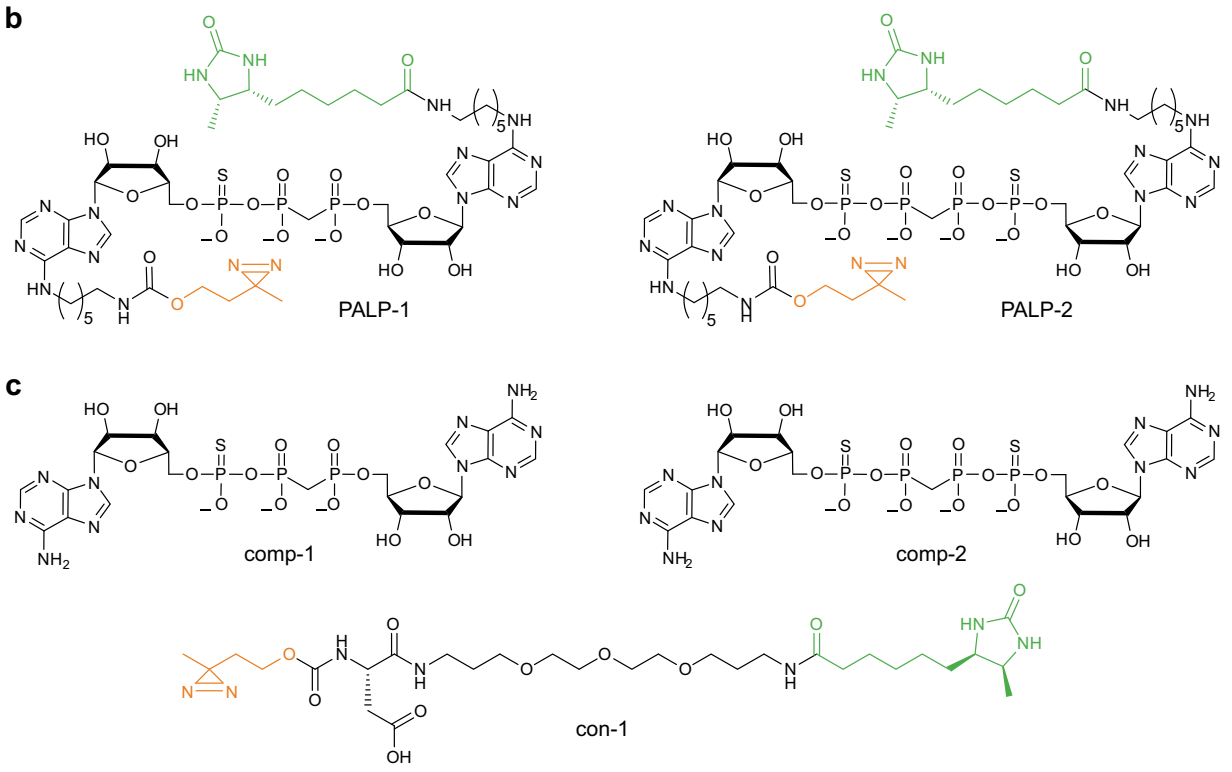

Fig. 1 Overview of photoaffinity-labeling (PAL) approach for identifying $\mathbf{A p}_{\mathbf{n}} \mathbf{A}$ interactors. a Schematic workflow of PAL experiments. Probes were incubated with cell lysates and irradiated with UV light to initiate photo-crosslinking. Labeled proteins were affinity-purified using desthiobiotin (DTB) as affinity tag. Eluted fractions were digested and analyzed by LC-MS/MS and label-free quantification (LFQ). b Functionalized, non-hydrolysable Ap ${ }_{3} A$ and $A p_{4} A$ derivatives used as PAL probes (PALP). c Unlabeled, non-hydrolysable $A p_{3} A$ and $A p_{4} A$ derivatives and a control substance (con-1) lacking the $A p_{n} A$ scaffold served as controls in PAL experiments. 
chemical proteomics approach based on the synthesized PALPs and uncovers proteome-wide interaction maps for $\mathrm{Ap}_{3} \mathrm{~A}$ and $\mathrm{Ap}_{4} \mathrm{~A}$. This provides a rich source for further functional studies directed towards a deeper understanding of the physiological and patho-physiological roles of these nucleotides.

\section{Results}

Design and synthesis of PALPs. To unravel the interactome of $\mathrm{Ap}_{3} \mathrm{~A}$ and $\mathrm{Ap}_{4} \mathrm{~A}$ we designed and employed photoaffinitylabeling probes that contain surrogates of the phosphoanhydride bonds in order to confer hydrolytic stability, as we observed that natural $\mathrm{Ap}_{n} \mathrm{As}$ are hydrolyzed to different extent in cell lysates (Supplementary Fig. 1). Previous studies showed that the stability of $\mathrm{Ap}_{n}$ As in cell lysates is increased by exchanging the $\mathrm{P}_{\alpha}$ oxygen for sulfur and replacing the bridging oxygen with a methylene group ${ }^{13}$. Therefore, we synthesized the $\mathrm{Ap}_{3} \mathrm{~A}$-analog PALP-1 and $\mathrm{Ap}_{4} \mathrm{~A}$-analog PALP-2 (Fig. 1b) that contain thiomonophosphate at the $a$-phosphate positions ${ }^{14}$ and methylene bisphosphonate ${ }^{15}$ linkages.

Due to the proficiency of several enzymes to use N6-modified ATP and N6-modified $\mathrm{Ap}_{3} \mathrm{~A}$ as substrates, the N6 positions of the adenosine moieties were chosen for the attachment of the photocrosslinking diazirine (DA) and the affinity tag desthiobiotin (DTB) in our probes ${ }^{16-18}$. The used DA represents a small functional group that undergoes carbene formation under UV light that rapidly inserts into nearby $\mathrm{C}-\mathrm{H}, \mathrm{N}-\mathrm{H}$, and $\mathrm{O}-\mathrm{H}$ bonds, rendering DAs well-established tools for photoaffinity labeling ${ }^{19,20}$. DTB as affinity tag allows enrichment of tagged proteins by exploiting the affinity of DTB to (strept)avidin, and its specific elution with biotin for subsequent analysis by high-resolution mass spectrometry $(\mathrm{MS})^{21,22}$. The synthesis of both probes was straightforward and is described in detail in Supplementary Figs. 2 and 3. To further increase the specificity of our approach, two non-photoreactive derivatives comp-1 and comp-2 (Fig. 1c) were synthesized following described routes ${ }^{23,24}$ and employed in competition experiments. Similarly, to exclude proteins from the interactomes that bind to the diazirine or desthiobiotin groups of our $\mathrm{Ap}_{3} \mathrm{~A}$ and $\mathrm{Ap}_{4} \mathrm{~A}$ probes, molecule con-1 was synthesized (Fig. 1c) and applied as an additional control.

$A p_{3} A$ and $A p_{4} A$ are present in HEK293T cell lysates. As HEK293 cells are commonly used in interactome analyses and already have been employed to study the correlation between intracellular $\mathrm{Ap}_{3} \mathrm{~A}$ concentrations and apoptosis ${ }^{25}$, we chose the HEK293T cell line for our experiments. To obtain further insights into the responsiveness of HEK293T cells towards external stress, we determined the cellular levels of $A_{3} A$ and $A p_{4} A$ and their changes upon exposure to different stress conditions such as mitomycin C (MMC)-induced DNA damage and oxidative stress by treatment with $\mathrm{H}_{2} \mathrm{O}_{2}$. To do so, we developed a method to quantify $\mathrm{Ap}_{3} \mathrm{~A}$ and $\mathrm{Ap}_{4} \mathrm{~A}$ levels in cell lysates via high-resolution electrospray ionization mass spectrometry (HR-ESI-MS) employing synthesized ${ }^{13} \mathrm{C}$-labeled compounds ${ }^{13} \mathrm{C}_{10}-\mathrm{Ap}_{3} \mathrm{~A}$ and ${ }^{13} \mathrm{C}_{10}-\mathrm{Ap}_{4} \mathrm{~A}$ as internal standards (Fig. 2a). By this, we determined the level of $A_{3} A$ to be $0.7 \pm 0.1$ pmol per $10^{6}$ cells and of $\mathrm{Ap}_{4} \mathrm{~A}$ level at $0.9 \pm 0.4$ pmol per $10^{6}$ cells under unstressed conditions, while their levels significantly increased upon treatment of cells with MMC or $\mathrm{H}_{2} \mathrm{O}_{2}$ (Fig. 2b). These results confirm that $\mathrm{Ap}_{3} \mathrm{~A}$ and $\mathrm{Ap}_{4} \mathrm{~A}$ are present in HEK293T cells and their concentration increases upon exposure to stressors.

Proteomic profiling of the $\mathrm{Ap}_{3} \mathrm{~A}$ and $\mathrm{Ap}_{4} \mathrm{~A}$ protein interactome. Next, we tested the synthesized probes for PAL of proteins with HEK293T cell lysates. To this end, the $\mathrm{Ap}_{n} \mathrm{~A}$ derivatives PALP-1 and PALP-2 were first incubated with HEK293T cell lysates. The samples were then irradiated with UV light $(365 \mathrm{~nm})$ to initiate the photo-crosslinking reaction and the labeled proteins were affinity-enriched via streptavidincoated Sepharose ${ }^{\mathrm{TM}}$ beads. After washing the beads thoroughly, the bound proteins were eluted with biotin. The eluted proteins were resolved by SDS-PAGE and subsequently analyzed by western blotting using ExtrAvidin ${ }^{\circledR}$-Peroxidase. Aiming for high photo-crosslinking yields and selectivity at the same time, we optimized the experimental conditions with regard to the incubation and irradiation times as well as the concentrations of bait and competitor molecules (Fig. 3a and Supplementary Fig. 4).

For LC-MS/MS analysis of bound proteins, triplicates of PAL experiments with PALP-1 and PALP-2 were performed using HEK293T cell lysates. We conducted several control experiments including (i) experiments without UV irradiation, (ii) PAL experiments using con-1 as control substance, and (iii) experiments without addition of any PALPs to the cell lysates. After data processing (see below), only proteins that were enriched compared to these negative controls were included in our lists (Supplementary Data 1). In order to further limit the number of false positive hits, we conducted competition experiments using PALP-1 and PALP-2 in the presence of the respective unlabeled $\mathrm{Ap}_{\mathrm{n}} \mathrm{A}$ analogs comp-1 and comp-2. For the final lists, only proteins that were enriched with PALP-1 and PALP-2 in the absence of comp-1 and comp-2, but not in their presence, were considered (Fig. 3c).

After affinity enrichment, proteins in the eluted fractions were resolved by SDS-PAGE and digested for LC-MS/MS analysis. Three replicates of this process were analyzed and measured as technical duplicates by LC-MS/MS to result in a total of six measurements per applied condition. PA-labeled proteins were identified by MaxQuant and quantified by $\mathrm{LFQ}^{26,27}$. The data was further analyzed by Perseus ${ }^{28}$ resulting in 732 identified proteins for PALP1 and 802 identified proteins for PALP-2. For these proteins, missing value imputation (downshift 1.8 , width 0.3 ) in the total matrix mode and multiple-sample tests $\left(\mathrm{FDR} \leq 0.01, S_{0}=0.2\right)$ were performed. Under these conditions, 56 proteins were identified as significant by ANOVA statistics for the PALP-1 experiment, 53 of which were significantly enriched after pairwise comparison to Tukey's honest significant difference (THSD, FDR $\leq 0.05$ ) and subsequent filtering against the three negative control experiments. These proteins were further filtered for significance against proteins enriched by the competitor control, resulting in 17 potential interaction partners for $\mathrm{Ap}_{3} \mathrm{~A}$ (Fig. 3c). Usage of the $A \mathrm{p}_{4} \mathrm{~A}$ analog PALP-2 revealed 86 significantly enriched proteins by ANOVA of which 81 showed significant enrichment in PALP-2 towards the three negative control experiments by the post hoc THSD test $(\mathrm{FDR} \leq 0.05)$. Of these proteins 26 showed significant enrichment against the competitor control (Fig. 3c).

Due to the low number of proteins identified with PALP-1, we decided to develop an additional PALP for $\mathrm{Ap}_{3} \mathrm{~A}$. Since $\mathrm{C} 2$-modifications in adenosines have been shown to be accepted by several nucleotide processing enzymes ${ }^{20,29,30}$, we synthesized (Supplementary Fig. 5) and applied PALP-3 (Fig. 3) as described above. With PALP-3, 538 proteins were identified, of which 341 were enriched against the negative controls, applying the same workflow as for PALP-1 and PALP-2. Comparison with the competitor experiments led to 49 significantly enriched proteins for PALP-3.

Proteins that were significantly enriched against all four controls after the ANOVA analysis $\left(S_{0}=0.2, \quad\right.$ FDR $\left.\leq 0.01\right)$ followed by a Tukey's post hoc THSD test were then visualized in heatmaps (Fig. 3; for heatmaps including proteins enriched by the control experiments see Supplementary Figs. 6 and 7). The 

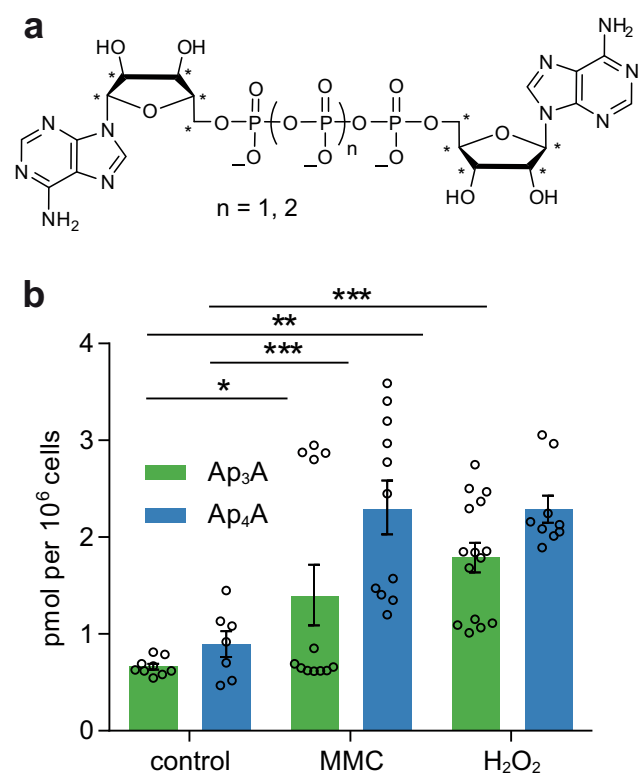

Fig. 2 Determination of $A p_{3} A$ and $A p_{4} A$ levels in HEK293T cell lysates. a Chemical structures of ${ }^{13} \mathrm{C}$-labeled ${ }^{13} \mathrm{C}_{10}-\mathrm{Ap}_{3} \mathrm{~A}(n=1)$ and ${ }^{13} \mathrm{C}_{10}-\mathrm{Ap}_{4} \mathrm{~A}$ $(n=2)$ used as internal standards. b Obtained $A p_{3} A$ (green) and $A p_{4} A$ (blue) levels of stressed and unstressed (control) HEK293T cells. For each condition 15 biological replicates were performed. Samples were measured in technical duplicates and averaged. Measurements with a signal to noise ratio below 7 were excluded. Data presented are mean \pm standard error of the mean (SEM); $n$ (control, $\left.A p_{3} A\right)=9, n$ (control, $\left.A p_{4} A\right)=7, n(M M C$, $\left.A p_{3} A\right)=12, n\left(M M C, A p_{4} A\right)=11, n\left(H_{2} O_{2}, A p_{3} A\right)=15, n\left(H_{2} O_{2}, A p_{4} A\right)=$ 9. Significant differences were determined by one-way ANOVA in combination with the Dunnett test $\left({ }^{\star} p \leq 0.05 ;{ }^{\star \star} p \leq 0.01 ;{ }^{\star \star \star} p \leq 0.001\right)$. Source data are provided as a Source Data file.

color scale represents the median $Z$-score normalized LFQ value as calculated by Perseus. Several proteins identified by PALP-1 were also found with PALP-2 or PALP-3 (Supplementary Fig. 8).

When inspecting the distribution of identified proteins for the respective probes (Fig. 3d), it becomes evident that in addition to nine shared hits, our approach also revealed exclusive hits for the $\mathrm{Ap}_{3} \mathrm{~A}$ probes (PALP-1 and PALP-3) and the $\mathrm{Ap}_{4} \mathrm{~A}$ probe (PALP2 ). Among those, we identified five aaRSs, which are known to play a major role in the synthesis of $\mathrm{Ap}_{\mathrm{n}} \mathrm{As}^{31}$. Furthermore, inosine- $5^{\prime}$-monophosphate dehydrogenase 2 (IMPDH2) was significantly enriched with PALP-3. In previous studies different variants of IMPDH have been shown to interact with $A p_{n} A s$ in binding-based and activity-based assays, indicating that this interaction plays a similar role in different organisms ${ }^{32,33}$.

The potential interaction partners for either $A_{3} A$ or $A p_{4} A$ were further analyzed using bioinformatic tools. With the program Cytoscape/Biological Network Gene Ontology $(\mathrm{BiNGO})^{34}$, enriched gene ontology (GO) terms were compared between the cohorts and the global proteome (Supplementary Data 2). We found for the proteins, which were enriched for $\mathrm{Ap}_{3} \mathrm{~A}$ by applying PALP- 1 and PALP-3, that $31 \%$ are involved in cellular response to chemical stimuli and $11 \%$ in response to oxygen levels (Fig. 3e). Both terms were not found to be enriched for the proteins identified with the $\mathrm{Ap}_{4} \mathrm{~A}$ analog PALP-2. Regarding $\mathrm{Ap}_{4} \mathrm{~A}$, a total of $46 \%$ of the proteins that were identified with PALP-2 are involved in gene expression and $19 \%$ in protein targeting (Fig. 3e). Both terms were not enriched in the proteins identified with PALP-1 or PALP-3. GO terms that were prevalent for both $\mathrm{Ap}_{3} \mathrm{~A}$-based and $\mathrm{Ap}_{4} \mathrm{~A}$-based probes, even though to a varying extent, include translation $(13 \%$ in
$\mathrm{Ap}_{3} \mathrm{~A}$-based and $35 \%$ in $\mathrm{Ap}_{4} \mathrm{~A}$-based probes) and tRNA aminoacylation (7\% in $\mathrm{Ap}_{3} \mathrm{~A}$-based and $15 \%$ in $\mathrm{Ap}_{4} \mathrm{~A}$-based probes).

Notably, the majority of the identified proteins appear to be involved in metabolic processes ranging from those of carboxylic acids to nucleotides and carbohydrates (Fig. 3e and Supplementary Data 2). Exemplarily, proteins contributing to the metabolism of carboxylic acids were enriched in all our samples ( $41 \%$ for PALP-1 and PALP-3 and 38\% for PALP-2). Another process that seems to be connected to both $A_{3} \mathrm{~A}$ and $\mathrm{Ap}_{4} \mathrm{~A}$ is $\mathrm{RNA}$ processing. Taken together, 11 proteins (14\%) were identified with the three PALPs that are associated with RNA processing, of which 7 (9\%) are involved in mRNA splicing. In addition, several molecular functions were found to be enriched in our data sets (Supplementary Data 2). Interestingly, out of the 78 overall identified proteins, only $36(46 \%)$ are known nucleotide binders whereof $25(32 \%)$ are ATP binders. This indicates that $\mathrm{Ap}_{3} \mathrm{~A}$ and $\mathrm{Ap}_{4} \mathrm{~A}$ are not just ATP surrogates ${ }^{2,32}$ but have roles in cellular pathways that are distinguishable from those of other nucleotides.

$\mathrm{Ap}_{\mathbf{n}} \mathbf{A s}$ are substrates for DcpS. As mentioned above, 11 proteins involved in RNA processing were identified, including several ribonucleoproteins (HNRNPL, HNRNPA3, HNRNPA2B1 and HNRNPR) which were identified with the $\mathrm{Ap}_{4} \mathrm{~A}$-based PALP-2 and the decapping scavenger protein (DcpS, Fig. 4a) found with PALP-2 and PALP-3. DcpS belongs to the HIT family and is responsible for the very last step of mRNA degradation. Its main substrates are $5^{\prime}-5^{\prime}$ linked dinucleoside triphosphates $\left(\mathrm{m}^{7} \mathrm{Gp}_{3} \mathrm{~N}\right)$ that form the protective cap structure of eukaryotic mRNA ${ }^{35,36}$. The cap structure is selectively cleaved at the phosphate in proximity to $\mathrm{m}^{7} \mathrm{G}$, yielding $\mathrm{m}^{7} \mathrm{GMP}$ and NDP (Fig. $4 \mathrm{~b}$ ).

To investigate the cleavage reaction of the cap analog $\mathrm{m}^{7} \mathrm{Gp}_{3} \mathrm{G}$ in the presence of $\mathrm{Ap}_{3} \mathrm{~A}$ or $\mathrm{Ap}_{4} \mathrm{~A}$, an HPLC-based assay was developed. To this end, $m^{7} \mathrm{Gp}_{3} \mathrm{G}$ was incubated with $\mathrm{DcpS}$ in the presence and absence of $\mathrm{Ap}_{3} \mathrm{~A}$ or $\mathrm{Ap}_{4} \mathrm{~A}$. The progress of the reaction was monitored by HPLC (Fig. 4c and Supplementary Fig. 9). In addition to the expected cleavage products, ATP, ADP, and AMP were found in the reactions with $A p_{n} A$ derivatives, demonstrating that both $\mathrm{Ap}_{3} \mathrm{~A}$ and $\mathrm{Ap}_{4} \mathrm{~A}$ can be cleaved by $\mathrm{DcpS}$. Quantification of GDP at different time points showed that cleavage of $m^{7} \mathrm{Gp}_{3} \mathrm{G}$ was to some extent impaired when incubated with either $\mathrm{Ap}_{3} \mathrm{~A}$ or $\mathrm{Ap}_{4} \mathrm{~A}$ (Fig. 4d).

UBA1 accepts $A p_{4} A$ as $A T P$ surrogate but not $A p_{3} A$. Ubiquitin-like modifier-activating enzyme 1 (UBA1) was among the most significantly enriched hits for $\mathrm{Ap}_{4} \mathrm{~A}$ (PALP-2), whereas it was less enriched with $\mathrm{Ap}_{3} \mathrm{~A}$ (PALP-1 and PALP-3, Fig. 5a). UBA1 catalyzes the first reaction of the ubiquitin (Ub) conjugation cascade, namely the activation of $\mathrm{Ub}^{37}$. In this reaction, $\mathrm{Ub}$ is first adenylated at its carboxyl terminus in an ATP-dependent manner and then transferred to a conserved cysteine residue of UBA1 via thioester bond formation. Finally, Ub is transferred to an E2 enzyme by a transthioesterification reaction (Fig. 5b).

As it has already been reported that UBA1 is able to synthesize $\mathrm{Ap}_{4} \mathrm{~A}$ in vitro ${ }^{7}$, we investigated if $A p_{3} \mathrm{~A}$ and $\mathrm{Ap}_{4} \mathrm{~A}$ can substitute for ATP in the Ub cascade. Therefore, the UBA1-catalyzed activation of $\mathrm{Ub}$ and the consecutive transfer to the E2 enzyme UbcH7 was investigated as a model system. By incubating the enzyme mix with $\mathrm{Ap}_{4} \mathrm{~A}$ in the absence of ATP, the formation of a UbcH7 Ub thioester complex was observed after 1 and $5 \mathrm{~min}$ by non-reducing SDS-PAGE analysis, whereas this was not observed for $\mathrm{Ap}_{3} \mathrm{~A}$ (Fig. 5c). To confirm that the effect derives from $\mathrm{Ap}_{4} \mathrm{~A}$ itself and not from potential contamination with ATP, the different nucleotides were pre-treated with shrimp-alkaline phosphatase (SAP, Fig. 5d). As expected, Ub activation and, 
a

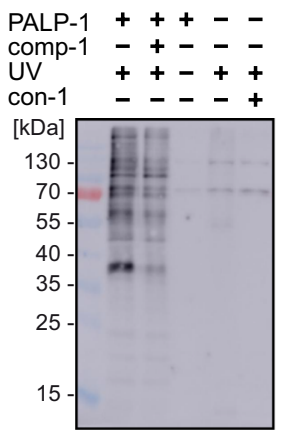

C

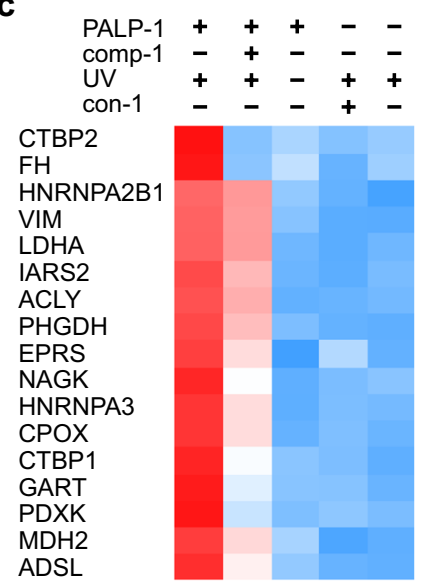

d

PALP-2

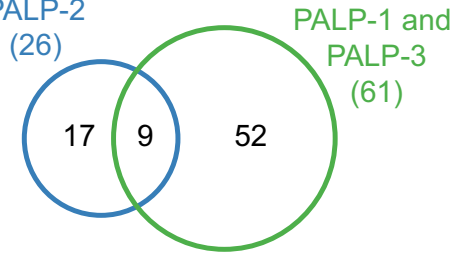

e

cellular response to chemical stimulus
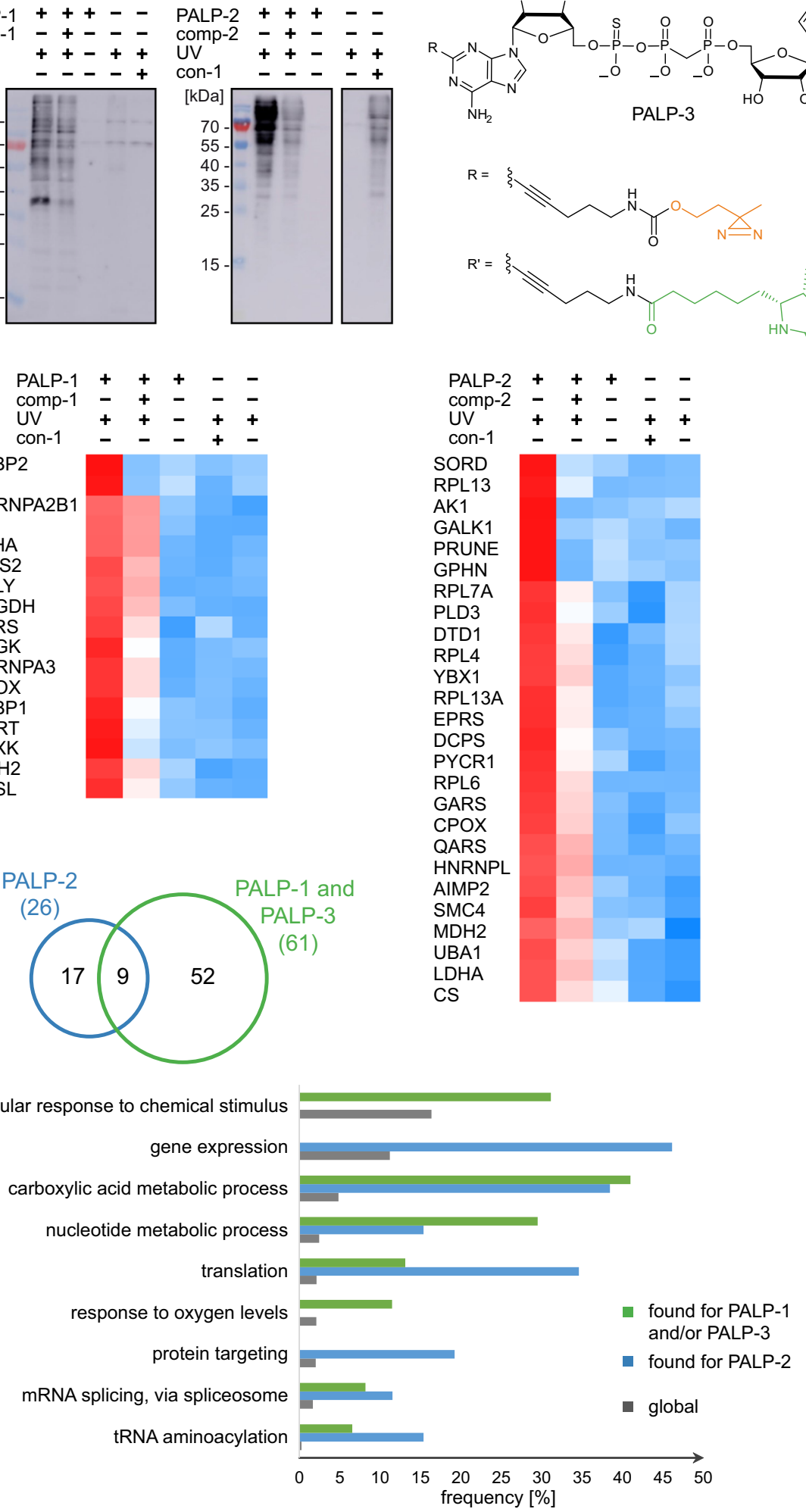

$\mathrm{R}=$<smiles>CC#CCCCNC(=O)OCCC1(C)N=N1</smiles>

$R^{\prime}=\xi$

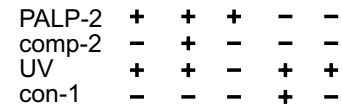

SORD

RPL13

AK1

GALK1

PRUNE

GPHN

RPL7A

PLD3

DTD1

YBX1

RPL13A

EPRS

DCPS

PYCR1

RPL6

GARS

CPOX

QARS

HNRNPL

AIMP2

SMC4

$\mathrm{MDH} 2$

UBA1

LDHA

CS

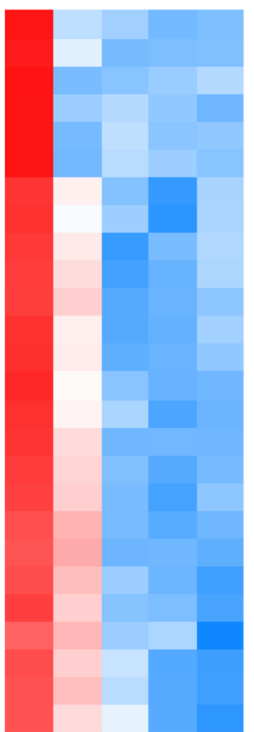

b

PALP-3 + + + - -

UV + \pm-+

con-1 $-\mathbf{t}-\mathbf{+}$

130 -

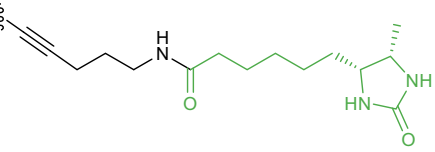

PA

comp-1 $-++\quad+\quad-$

UV $++t++$

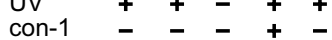

con-1

GGH

PABPC1

PDIA3

DCPS

ANP32A

GPD1L

CKMT1A

SSBP1

CKB

LDHA

RARS

ACADM

ACAD

ATIC

MRPL46

CPOX

SUCLA2

OAT

LDHB

CBR1

AIP

IMPDH2

IMPDH2

KARS

PGK1

$\mathrm{MDH}$

CS

PLD3

DLD3

DCTPP1

PABPC4

ADSL

AIFM1

GNPNAT

PPAT

ACO2

$\mathrm{FH}$

PRUNE

MAPK1

RPS6KA3

PMVK

UPP1

PSMC5

AK1

AK1

PDXK
REXO2

AK4

CMPK1

PSMB3
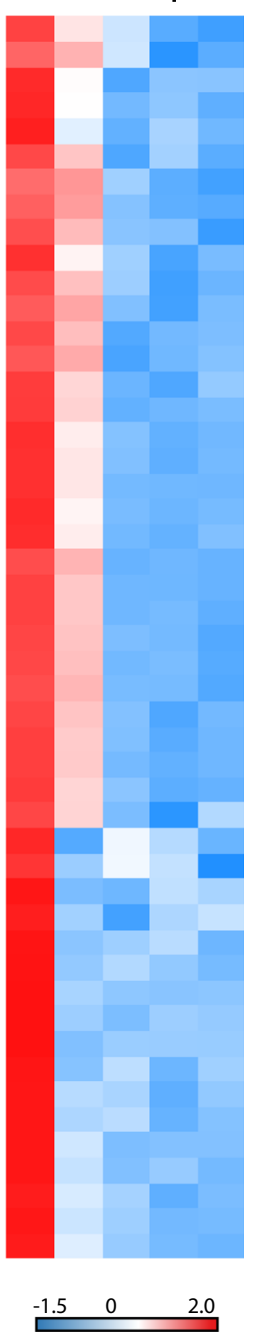

relative enrichment thus, UbcH7 Ub thioester complex formation was not observed for ATP, while it was detected when $\mathrm{Ap}_{4} \mathrm{~A}$ was employed.

LDHA and PGK1 bind to a fluorescent labeled $\mathrm{Ap}_{3} \mathrm{~A}$ analog. As mentioned before, the majority of the proteins enriched with the used PALPs are involved in metabolic processes. Among the most prominent hits were LDHA (found for all PALPs) and
PGK1 (found with PALP-3), which showed strong enrichment in our PAL experiments compared to the controls (Fig. 6a). Additionally, recent reports document that besides their functions as (post-)glycolytic enzymes, both proteins are reported to have non-metabolic functions including involvement in tumorigenesis and stress response ${ }^{38,39}$. To investigate the interactions between these proteins and $\mathrm{Ap}_{n} \mathrm{As}$, we developed a method to measure 
a

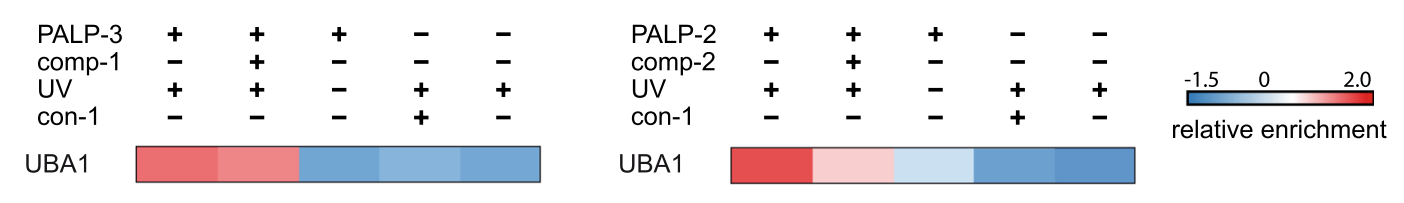

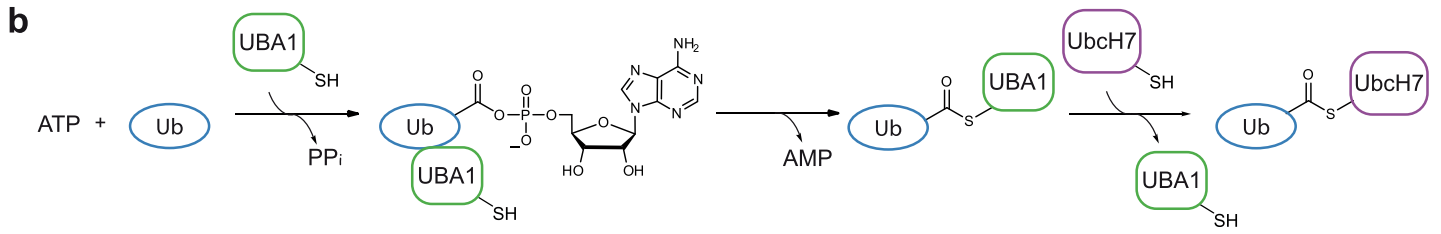

C
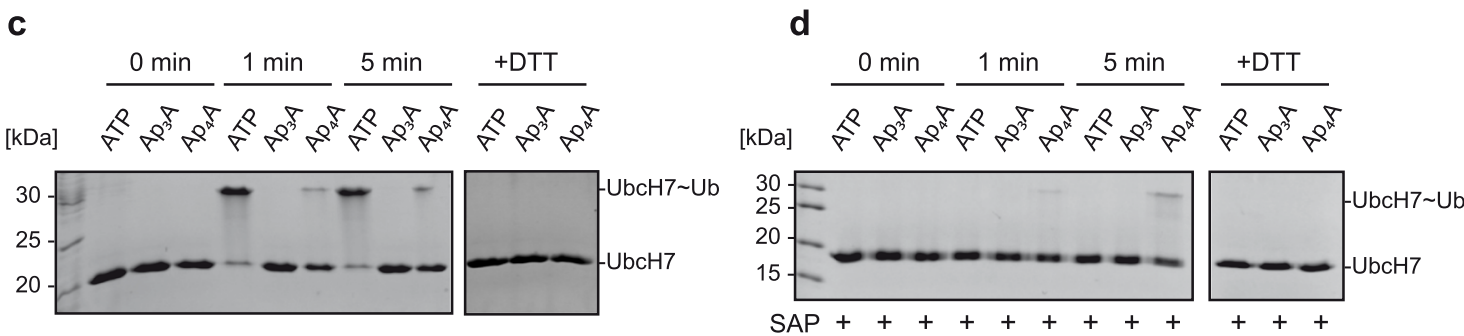

Fig. 5 Investigation of the interaction of $\mathbf{A p}_{\mathbf{n}} \mathbf{A s}$ with UBA1. a Extract of ANOVA-heatmap (Z-scores) for UBA1 under different PAL conditions. b ATPdependent $\mathrm{Ub}$ activation and transthioesterification reactions catalyzed by UBA1. c Detection of Ub transfer from UBA1 to UbcH7 in the presence of $A p_{3} A$, $\mathrm{Ap}_{4} \mathrm{~A}$ or ATP, analyzed by non-reducing SDS-PAGE (15\%) followed by Coomassie blue staining. $\mathbf{d}$ The nucleotides were incubated with SAP before performing the transthioesterification reaction to remove possible contaminants of $A T P$ in the $A p_{3} A$ and $A p_{4} A$ samples. The experiments were performed twice with matching results. Source data are provided as a Source Data file.

a

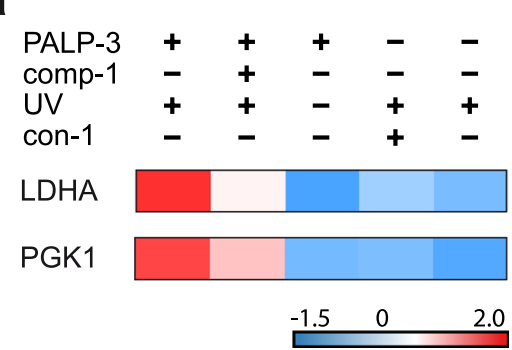

relative enrichment

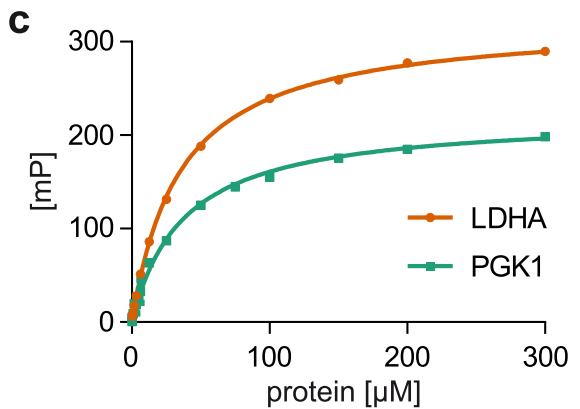

protein $[\mu \mathrm{M}]$

HO

b

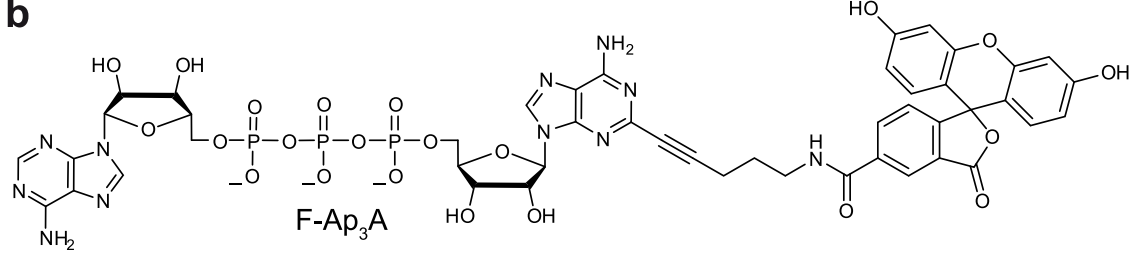

Fig. 6 Investigation of the binding affinity of LDHA and PGK1 to the fluorescent labeled $A p_{3} A$ analog $F-A p_{3} A$ via fluorescence polarization (FP). a Extract of ANOVA-heatmap (Z-scores) for LDHA and PGK1 under different PAL conditions. $\mathbf{b}$ Chemical structure of F-A $p_{3} A$. $\mathbf{c} F P$-based quantification of binding between LDHA (orange) or PGK1 (green) to $F-A p_{3} A$. Increasing concentrations of protein were incubated with $F-A p_{3} A$ ( $25 n M$ ) for 15 min on ice and $30 \mathrm{~min}$ at $30^{\circ} \mathrm{C}$ before measurement. FP values were determined and plotted against the protein concentrations. Data presented are mean $\pm S D, n=3$ technical replicates. Source data are provided as a Source Data file.

ANOVA statistics (FDR $\left.\leq 0.01, S_{0}=0.2\right)$ and subsequent analysis of the hits by THSD test (FDR $\leq 0.05)$. The proteins identified and their $Z$-score normalized median LFQ values measured in the different conditions were displayed in a combined heatmap (Fig. 7b, Supplementary Data 3 and Supplementary Fig. 10). Interestingly, the distribution of the hits retrieved with the $\mathrm{Ap}_{3} \mathrm{~A}$-based and $\mathrm{Ap}_{4} \mathrm{~A}$-based probes with $E$. coli $\mathrm{K} 12$ lysates was similar to the one obtained with eukaryotic HEK293T cells. GO analysis showed significant enrichment for various metabolic pathways, including carboxylic acid metabolism (more than 50\% in both cases), nucleotide metabolism (more than $40 \%$ in both cases), and carbohydrate catabolism (more than $20 \%$ in both cases) (Fig. $7 \mathrm{~d}$ and Supplementary Data 4). Also, out of the 20 identified hits, 11 (55\%) are known nucleotide binders and $8(40 \%)$ are known ATP binders. Noteworthy, $40 \%$ of the hits are overlapping for PALP-2 and PALP-3 probes (Fig. 7c), which is significantly higher than for the proteins identified from HEK293T cell lysates, where only $12 \%$ were overlapping.

We finally investigated the human orthologues of the bacterial hits using the PANTHER (Protein ANalysis THrough Evolutionary Relationship) bioinformatics resource ${ }^{42}$. Two of the most prominent hits, enriched in PAL experiments using HEK293T and E. coli lysates, were the phosphoglycerate kinase, encoded by the $p g k$ gene 
a

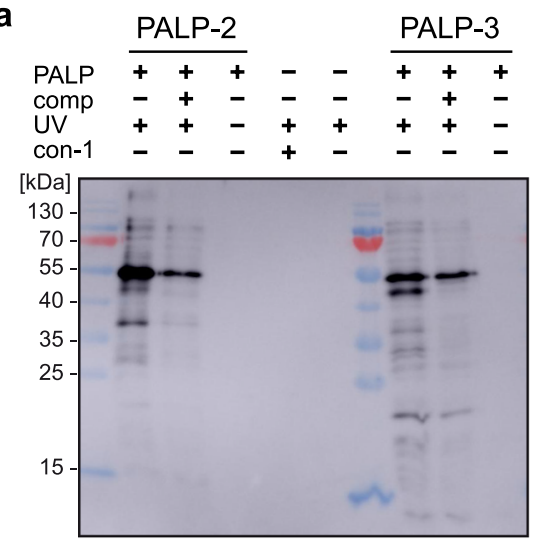

C

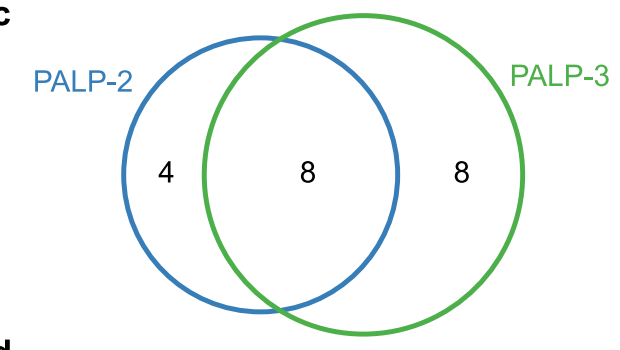

d b

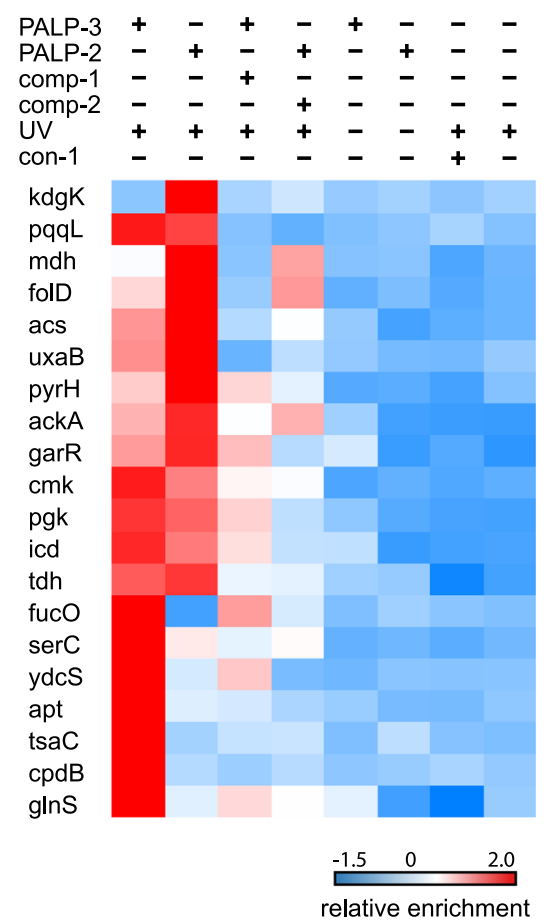

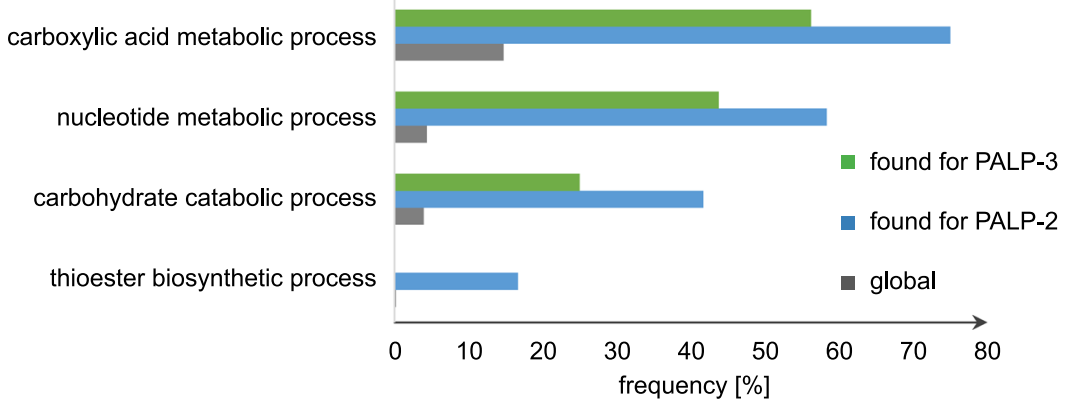

Fig. 7 Proteomic analysis of PAL experiments using E. coli cell lysates. a Western blot analysis with ExtrAvidin ${ }^{\circledR}$-Peroxidase showing enrichment of labeled proteins under optimized conditions using PALP-2 and PALP-3 as indicated after irradiation with UV light ( $365 \mathrm{~nm}$ ) for 5 min. b Heatmap representation (Z-scores) of proteins that were quantified in the respective experiments in at least four out of six measurements and that passed a oneway ANOVA-based multiple-sample test for statistically significant enrichment, with a permutation-based false discovery rate (FDR) below or equal to 0.01 and $S_{0}$ value set to 0.2 , followed up by two-sided post hoc Tukey's HSD test (FDR $\leq 0.05$ ) to determine proteins enriched against all performed control experiments. c Venn diagram illustrating the overlap of identified proteins with PALP-3 (green) and PALP-2 (blue). d Frequencies of the enriched GO terms are compared between PALP-3 (green) and PALP-2 (blue) and the global E. coli proteome (gray) according to GO analysis using a one-sided hypergeometric test performed with the Cytoscape BiNGO resource (Supplementary Data 4). Global frequency represents the number of genes annotated to a GO term in the entire E. coli proteome, while sample frequency represents the number of genes annotated to that GO term in the protein list obtained by PAL. Source data are provided as a Source Data file.

in bacteria and by PGK1 in humans, and the malate dehydrogenase, encoded by $m d h$ in bacteria and $M D H 1$ and $M D H 2$ in humans. Interestingly, phosphoglycerate kinase and malate dehydrogenase are both involved in carbohydrate metabolism, as well as LDHA and GALK1 that we identified in HEK293T cell lysates, highlighting potential common roles of $\mathrm{Ap}_{\mathrm{n}} \mathrm{As}$ in bacteria and eukarya. Furthermore, the bacterial orthologue of the aaRS QARS $(g \ln S)$ was found, showing further similarities in our results.

\section{Discussion}

Even though $\mathrm{Ap}_{3} \mathrm{~A}$ and $\mathrm{Ap}_{4} \mathrm{~A}$ were discovered in the $1960 \mathrm{~s}^{1}$, their cellular roles and functions remain enigmatic. Here, we report proteome-wide interaction maps of $\mathrm{Ap}_{3} \mathrm{~A}$ and $\mathrm{Ap}_{4} \mathrm{~A}$ by employing probes for PAL in combination with MS-based proteomics. In comparison to previous affinity enrichment studies $^{32,43,44}$ that relied on non-covalent interactions between
$\mathrm{Ap}_{\mathrm{n}} \mathrm{As}$ and potential binders, our study is based on covalently connecting $\mathrm{Ap}_{3} \mathrm{~A}$-based and $\mathrm{Ap}_{4} \mathrm{~A}$-based probes to their target proteins allowing for both trapping transient interactions and thorough washing steps in order to minimize false positive hits. Given the relatively small size of the chemical modifications in the PALPs in comparison to the dimensions of an average protein also renders covalent "trapping" of indirect interaction partners of $\mathrm{Ap}_{\mathrm{n}} \mathrm{A}$ unlikely, even though it cannot fully be excluded.

The earlier studies $32,43,44$ exclusively investigated $\mathrm{Ap}_{4} \mathrm{~A}$ and mostly E. coli cells. Albeit less rigorous investigations and analysis were conducted (i.e., fewer repetitions and less rigorous statistical analysis), only $6-13$ proteins were identified. Furthermore, there is little overlap in identified proteins between these studies and compared to our studies.

Overall, we identified 78 proteins from HEK293T cell lysates that potentially interact with $\mathrm{Ap}_{3} \mathrm{~A}$ and $\mathrm{Ap}_{4} \mathrm{~A}$ after rigorous 
statistical analysis. Only about half of these are known nucleotide binding proteins, indicating a broader scope of the roles of $\mathrm{Ap}_{3} \mathrm{~A}$ and $\mathrm{Ap}_{4} \mathrm{~A}$ in cellular processes beyond nucleotide-processing and speaking against the hypothesis that $\mathrm{Ap}_{\mathrm{n}} \mathrm{As}$ merely act as ATPsurrogates $^{32}$. In fact, our chemical proteomics study uncovered interactions that are specific for either $A_{3} \mathrm{~A}$ or $\mathrm{Ap}_{4} \mathrm{~A}$ and interactions that are shared by both $A p_{n} A s$, again pointing towards broader and specific roles of the respective nucleotides.

The majority of the proteins found to interact with $\mathrm{Ap}_{3} \mathrm{~A}$ and $\mathrm{Ap}_{4} \mathrm{~A}$ probes appear to be involved in metabolic processes ranging from those of carboxylic acid to nucleotides and carbohydrates (Fig. 3e and Supplementary Data 2). Besides these common interactions, $\mathrm{Ap}_{3} \mathrm{~A}$ appears to play a role in cellular response to e.g., chemical stimuli and changing oxygen levels, which may correlate to the observed changes in $\mathrm{Ap}_{3} \mathrm{~A}$ levels in HEK293T cell lysates upon stress induced by mitomycin $C$ and $\mathrm{H}_{2} \mathrm{O}_{2}$. For $\mathrm{Ap}_{4} \mathrm{~A}$ we identified a variety of proteins involved in gene expression, translation and protein targeting, as well as UBA1, an essential enzyme of the Ub system, whose interaction with $\mathrm{Ap}_{4} \mathrm{~A}$ we could demonstrate in a case study (Fig. 5) ${ }^{37}$. Taken together, our results support the hypothesis that $\mathrm{Ap}_{3} \mathrm{~A}$ and $\mathrm{Ap}_{4} \mathrm{~A}$ are alarmones that signal various stress conditions ${ }^{2,45-47}$.

Our PAL studies also discovered the involvement of $\mathrm{Ap}_{3} \mathrm{~A}$ and $\mathrm{Ap}_{4} \mathrm{~A}$ in RNA-associated processes. Proteins involved in tRNA aminoacylation and mRNA splicing are overrepresented among the proteins found with either probe. We also identified several proteins that are connected to regulation of translation. This is particularly interesting since recent studies report on the involvement of dinucleoside polyphosphates in RNA cap formation in bacteria. Luciano et al. showed that $\mathrm{Np}_{4} \mathrm{As}$ can be used as precursors for RNA cap structures that serve as primers for the $E$. coli RNA polymerase ${ }^{48}$. Furthermore, Hudeček et al. reported that both $\mathrm{Ap}_{3} \mathrm{~A}$ and $\mathrm{Ap}_{4} \mathrm{~A}$ can be incorporated into bacterial RNA caps ${ }^{49}$. Likewise, our PAL study identified the decapping scavenger enzyme $\mathrm{DcpS}$ as $\mathrm{Ap}_{\mathrm{n}} \mathrm{A}$-binder. Using additional followup assays, we demonstrated that $\mathrm{Ap}_{3} \mathrm{~A}$ and $\mathrm{Ap}_{4} \mathrm{~A}$ can act as alternative substrates for the latter (Fig. 4), and thereby slow down the cleavage of cap analogs. All these results point at a potential role of these $\mathrm{Ap}_{n} \mathrm{As}$ in the regulation of RNA stability, metabolism, and/or transport.

Investigations of $E$. coli K12 cells revealed a total of 20 target proteins for $\mathrm{Ap}_{3} \mathrm{~A}$ and/or $\mathrm{Ap}_{4} \mathrm{~A}$. Again, only about half of the identified proteins were known nucleotide binders, comparable to the results obtained for HEK293T cells. Moreover, similar to the results obtained with HEK293T cells, proteins involved in various metabolic pathways, including carboxylic acid metabolism, nucleotide metabolism, and carbohydrate catabolism were found to be enriched using E. coli extracts indicating potentially conserved functions of these $A p_{n} A s$ in bacterial and eukaryotic cells. Two metabolic enzymes identified from E. coli lysates were the phosphoglycerate kinase and the malate dehydrogenase, proteins whose human orthologues we also found in HEK293T. Interestingly, both enzymes are involved in carbohydrate metabolism, which is the case for several proteins we identified in E. coli and HEK293T, such as pgk, mdh, PGK1, MDH2, LDHA, and GALK1. Recent reports showed that various metabolic enzymes including PGK1, LDHA, and MDH2 have non-metabolic functions in processes including tumorigenesis and stress response, making them interesting candidates for follow-up experiments ${ }^{35,36}$. To further investigate the interaction between $\mathrm{Ap}_{\mathrm{n}} \mathrm{As}$ and these proteins, we measured binding affinities between PGK1 and LDHA and a fluorescein-labeled $\mathrm{Ap}_{3} \mathrm{~A}$ probe and obtained $K_{\mathrm{D}}$ values in the $10^{-5} \mathrm{M}$ range.

Overall, our approach based on PAL experiments with cell extracts combined with proteomics provides proteome-wide interaction maps for $\mathrm{Ap}_{3} \mathrm{~A}$ and $\mathrm{Ap}_{4} \mathrm{~A}$ in eukaryotic and bacterial cells. Still the proteins we identified as potential interaction partners of $A_{3} \mathrm{~A}$ and $\mathrm{Ap}_{4} \mathrm{~A}$ likely represent only a subset of their full interaction networks. One piece of evidence supporting this assumption is that the use of the differently modified $\mathrm{Ap}_{3} \mathrm{~A}$-based probes in PALP-1 and PALP-3 resulted in overlapping but also distinct hits, indicating a substrate bias that is inherent in the use of such chemical probes. This might also be the reason why several known interactors such as NUDT2 and FHIT were not identified. However, the applied control experiments and the rigorous statistics that we used for evaluation make it likely that significantly enriched proteins are also true positive interactors. Nonetheless, already at the present state, these maps represent a rich source that will hopefully spur and guide further investigations aimed at the elucidation of the hitherto enigmatic roles and functions of these nucleotides. Moreover, the $\mathrm{Ap}_{n} \mathrm{~A}-\mathrm{PAL}$ approach presented here opens up an avenue to discover the function and roles of these $\mathrm{Ap}_{n} \mathrm{As}$ e.g., by applying these PALPs and eventually new PALP scaffolds to different cell types exposed to external cues.

\section{Methods}

Chemical synthesis and characterization of compounds are described in the Supplementary Methods.

\section{Cell culture}

Growth conditions for human cells. HEK293T cells (ATCC) were grown in Dulbecco's modified Eagle medium (DMEM) supplemented with $10 \%(\mathrm{v} / \mathrm{v})$ fetal calf serum (FCS) and 100 units $/ \mathrm{mL}$ penicillin/streptomycin at $37^{\circ} \mathrm{C}$ and $5 \% \mathrm{CO}_{2}$. Cells were passaged every 2-3 days. For PAL experiments only passages up to 20 were used.

Growth conditions for E. coli K12 BW25113. Bacterial cells were grown in LB medium at $37^{\circ} \mathrm{C}$ and $200 \mathrm{rpm}$ overnight. For the main culture, LB medium was inoculated to a calculated $\mathrm{OD}_{600}$ of 0.01 with the overnight culture and grown for $5 \mathrm{~h}$ at $37^{\circ} \mathrm{C}$ to reach the late exponential growth phase. Cells were harvested by centrifugation $(3220 \times g)$ for $5 \mathrm{~min}$.

\section{Quantification of intracellular $A p_{3} A$ and $A p_{4} A$ in HEK293T cells under stress} conditions

No external stress. At $90 \%$ confluence, the cell dish was directly put on ice. The medium was removed and the cells were washed twice with $2 \mathrm{~mL}$ of ice-cold isotonic $\mathrm{NaCl}$ solution. One milliliter of $-80{ }^{\circ} \mathrm{C}$ lysing solution $\left(90 / 9 / 1 \mathrm{H}_{2} \mathrm{O}\right.$ / $\left.\mathrm{MeOH} / \mathrm{CHCl}_{3}(\mathrm{v} / \mathrm{v} / \mathrm{v})\right)$, as well as the internal standard solution $(20 \mu \mathrm{l}$ of $5 \mu \mathrm{M}$ ${ }^{13} \mathrm{C}_{10}-\mathrm{Ap}_{3} \mathrm{~A}$ and ${ }^{13} \mathrm{C}_{10}-\mathrm{Ap}_{4} \mathrm{~A}$ in water) was added to the cells and distributed evenly. After $15 \mathrm{~min}$ on ice, the lysed cells were scraped down and collected. The plate and the scraper were washed with $1 \mathrm{~mL}$ of lysing solution and the suspensions were combined. After centrifugation $\left(21,882 \times g, 4^{\circ} \mathrm{C}, 30 \mathrm{~min}\right)$ the supernatant was stored on ice and the pellet was ultrasonicated in $500 \mu \mathrm{L}$ lysing solution $(5 \mathrm{~min})$ and centrifuged again $\left(21,882 \times g, 4{ }^{\circ} \mathrm{C}, 30 \mathrm{~min}\right)$. The combined supernatants were evaporated in a SpeedVac Vacuum Concentrator (Thermo Fisher Scientific) and the residue was stored at $-20^{\circ} \mathrm{C}$ until further purification.

DNA damage via mitomycin C (MMC). At $90 \%$ confluence of the cells, MMC in $1 \times$ PBS was added to the dish to result in a final concentration of $100 \mathrm{nM}$ MMC in $10 \mathrm{~mL}$ medium. The cells were incubated for $18 \mathrm{~h}$ at $37^{\circ} \mathrm{C}$. After the treatment, the cells were treated in the same way as the unstressed samples.

Oxidative damage via hydrogen peroxide. At $90 \%$ confluence, the medium was removed, the cells were washed two times with $1 \times \mathrm{PBS}$ and $5 \mathrm{~mL}$ of a $500 \mu \mathrm{M} \mathrm{H}_{2} \mathrm{O}_{2}$ solution in $1 \times$ PBS was added. The cells were incubated for $20 \mathrm{~min}$ at $37^{\circ} \mathrm{C}$. The resulting cell suspension was transferred to a $15 \mathrm{~mL}$ falcon, the plate was washed with $4 \mathrm{~mL} 1 \times$ PBS and the suspensions were combined and centrifuged $(500 \times g$, $4{ }^{\circ} \mathrm{C}, 3 \mathrm{~min}$ ). The cell pellet was resuspended in $1 \mathrm{~mL}$ of $-80^{\circ} \mathrm{C}$ lysing solution and after $20 \mathrm{~min}$ of incubation on ice, the suspension was centrifuged $\left(3220 \times \mathrm{g}, 4^{\circ} \mathrm{C}\right.$, $5 \mathrm{~min})$. The supernatant was transferred in an Eppendorf tube and the pellet was resuspended and ultrasonicated in $1 \mathrm{~mL}$ lysing solution. After centrifugation $\left(3220 \times g, 4^{\circ} \mathrm{C}, 5 \mathrm{~min}\right)$ the supernatants were combined and evaporated in a SpeedVac Vacuum Concentrator (Thermo Fisher Scientific) and the residue was stored at $-20^{\circ} \mathrm{C}$ until further purification.

Purification via tC18 columns. The SepPak ${ }^{\circledR}$ tC18 column (Waters) was washed with $1 \mathrm{~mL} \mathrm{MeCN}$ and equilibrated with $2 \mathrm{~mL} 5 \% \mathrm{MeCN}$ in water. The cell extract was dissolved in $500 \mu \mathrm{L} 5 \% \mathrm{MeCN}$ in water and applied to the column. The eluted solution was collected, the column was washed with $1 \mathrm{~mL} 5 \% \mathrm{MeCN}$ in water and 
the combined extracts were freeze-dried. The resulting residue was dissolved in $50 \mu \mathrm{L}$ water and directly measured via LC-HR-ESI-MS.

Quantification of intracellular Ap3A and Ap4A. The purified cell extract was analyzed and quantified via LC-HR-ESI-MS (Bruker MicrOTOFII). A Hypercarb Porous Graphitic Carbon LC column $(5 \mu \mathrm{m}, 100 \times 2.1 \mathrm{~mm})$ was used in combination with a Hypercarb drop-in guard precolumn $(5 \mu \mathrm{m}, 10 \times 2.1 \mathrm{~mm})$. As mobile phase, $10 \mathrm{mM} \mathrm{NH}_{4} \mathrm{OAc}+0.1 \%$ diethylamine ( $\mathrm{pH}$ 10) (A) and $\mathrm{MeCN}$ (B) was used (gradient shown in Supplementary Table 2). For the calibration curve, different volumes of known concentrations of $\mathrm{Ap}_{3} \mathrm{~A}$ and $\mathrm{Ap}_{4} \mathrm{~A}$ were injected and linearly fitted. In every measured calibration sample, the same amount of internal standard ${ }^{13} \mathrm{C}_{10}-\mathrm{Ap}_{3} \mathrm{~A}$ and $\left.{ }^{13} \mathrm{C}_{10}-\mathrm{Ap}_{4} \mathrm{~A}\right)$ was present. The calibration curve was renewed for every experiment. To measure technical duplicates, every sample was injected twice $\left(20 \mu \mathrm{L}\right.$ each). For the calculation of the concentrations, the EICs of $\mathrm{Ap}_{3} \mathrm{~A}$ and $\mathrm{Ap}_{4} \mathrm{~A}$ $(\mathrm{m} / z=755.0747 \pm 0.02$ and $835.0410 \pm 0.02)$ were integrated and quantified. For the internal standard, the EICs of ${ }^{13} \mathrm{C}_{10}-\mathrm{Ap}_{3} \mathrm{~A}$ and ${ }^{13} \mathrm{C}_{10}-\mathrm{Ap}_{4} \mathrm{~A}$ $(\mathrm{m} / z=765.1082 \pm 0.02$ and $845.0740 \pm 0.02)$ were integrated and quantified. The resulting calculated concentrations of the technical duplicates were averaged. Exclusively measurements with a $S / N$ bigger than $S / N=7$ were considered for the calculation of concentrations. In case of insufficient spectrum quality or $S / N$ ratio of one of the duplicates only the duplicate of sufficient quality was considered for the calculation. The quantification of the samples and the standardization of the concentrations with the aid of the internal standards was done via Bruker Compass DataAnalysis (version 4.1) and Bruker Compass QuantAnalysis (version 2.1). Statistical tests were done using a one-way ANOVA in combination with the Dunnett test in GraphPad PRISM (version 6.01).

Cell lysate stability assay. The stability of $\mathrm{Ap}_{3} \mathrm{~A}$ and $\mathrm{Ap}_{4} \mathrm{~A}$ in HEK293T cell lysate was measured by RP-HPLC. To this end, $200 \mu \mathrm{M}$ nucleotides were incubated with or without $2 \mathrm{mg} / \mathrm{mL}$ HEK293T cell lysates in $20 \mathrm{mM}$ HEPES (pH 7.4), $100 \mathrm{mM} \mathrm{NaCl}, 5 \mathrm{mM} \mathrm{MgCl}_{2}$, and $1 \mathrm{mM}$ DTT at $37^{\circ} \mathrm{C}$ for $1 \mathrm{~h}$ in a volume of $45 \mu \mathrm{L}$. $15 \mu \mathrm{L}$ aliquots were taken at 0 and $60 \mathrm{~min}$ followed by the removal of proteins and salts by U-C4 ZipTips (Merck Millipore). The resulting mixture was diluted with $100 \mu \mathrm{L}$ water. $110 \mu \mathrm{L}$ sample was injected and analyzed by analytical RP-HPLC with a 250/4 mm NUCLEODUR C18 HTec column. The run was performed with $50 \mathrm{mM}$ aqueous triethylammonium acetate buffer (TEAA, $\mathrm{pH}$ 7.0) and $\mathrm{MeCN}$ as eluents (gradient shown in Supplementary Table 3).

\section{PAL experiments}

Preparation of HEK293T cell lysate. Cells were grown to $90 \%$ confluence. Before lysis, cells were centrifuged at $500 \times g$ at $4^{\circ} \mathrm{C}$ for $10 \mathrm{~min}$. Cell pellets were washed with cold $1 \times$ PBS $(3 \times 2 \mathrm{~mL})$, resuspended in cold lysis buffer $(25 \mathrm{mM}$ Tris $\cdot \mathrm{HCl}, \mathrm{pH}$ $7.5,150 \mathrm{mM} \mathrm{NaCl}, 1 \mathrm{mM}$ DTT, $1 \mathrm{mM}$ EDTA, $1 \% \mathrm{NP} 40,5 \%$ glycerol, $0.1 \mathrm{M}$ Pefabloc, $1 \mu \mathrm{g} / \mathrm{mL}$ aprotinin/leupeptin) and sonicated on ice at an amplitude of $10 \%$ for $10 \mathrm{~s}$, three times. Lysates were centrifuged at $4{ }^{\circ} \mathrm{C}$ and $19,064 \times g$ for $30 \mathrm{~min}$. The protein content of the supernatant was determined by BCA assay (Kit, Thermo Fisher Scientific). The supernatant was stored on ice until further use.

Preparation of E. coli K12 cell lysate. Pellets were stored on ice and washed with cold $1 \times$ PBS $(10 \mathrm{~mL})$. After repeating steps of centrifugation and washing in total of three times, the pellet was resuspended in cold lysis buffer $(25 \mathrm{mM}$ Tris. $\mathrm{HCl}, \mathrm{pH}$ 7.5, $150 \mathrm{mM} \mathrm{NaCl}, 1 \mathrm{mM}$ DTT, $1 \mathrm{mM}$ EDTA, $1 \%$ NP40, 5\% glycerol, $0.1 \mathrm{M}$ Pefabloc, $1 \mu \mathrm{g} / \mathrm{mL}$ aprotinin/leupeptin). The cell mixture was sonicated on ice at an amplitude of $20 \%$ for $30 \mathrm{~s}$, five times. The mixture was centrifuged at $4{ }^{\circ} \mathrm{C}$ and $19,064 \times g$ for $30 \mathrm{~min}$. The protein concentration in the supernatant was determined by BCA assay (Kit, Thermo Fisher Scientific). The supernatant was stored on ice until further use.

Photoaffinity labeling. In a total volume of $100 \mu \mathrm{L}$ the photoaffinity-labeling probe (PALP-1, PALP-2, or PALP-3, $20 \mu \mathrm{M})$ was incubated with lysate $(3.0 \mathrm{mg} / \mathrm{mL})$ in HEPES buffer $(50 \mathrm{mM}, 5 \mathrm{mM} \mathrm{MgCl} 2, \mathrm{pH} 6.8)$ for $2 \mathrm{~h}$ on ice in a 96 -well plate (Sarstedt) under protection from light. Afterwards, the well plate was positioned on ice under an UV lamp $\left(365 \mathrm{~nm}\right.$, distance approx. $\left.6 \mathrm{~cm}, 8 \mathrm{~mW} / \mathrm{cm}^{2}\right)$ for $5 \mathrm{~min}$. The mixture was incubated with streptavidin Sepharose ${ }^{\mathrm{TM}}$ high performance (GE Healthcare) beads $(35 \mu \mathrm{L}, 300 \mathrm{nmol} / \mathrm{mL}$ ) for $60 \mathrm{~min}$ at room temperature. The streptavidin beads were washed with $1 \times$ PBS $(3 \times 200 \mu \mathrm{L})$ and centrifuged (room temperature, $272 \times g, 3 \mathrm{~min}$ ) before use. After incubation, the samples were centrifuged (room temperature, $272 \times g, 3 \mathrm{~min}$ ) and the supernatant was removed. The beads were washed with $1 \times$ PBS containing $0.4 \%$ SDS $(3 \times 100 \mu \mathrm{L})$, aqueous urea solution $(6 \mathrm{M}, 2 \times 100 \mu \mathrm{L})$ and $1 \times$ PBS $(3 \times 100 \mu \mathrm{L})$ and centrifuged (room temperature, $272 \times g, 2 \mathrm{~min})$. After removing the supernatant, elution was performed with an aqueous biotin solution $(0.4 \mathrm{mM}, 2 \times 40 \mu \mathrm{L})$ and water $(1 \times 40 \mu \mathrm{L})$ at $37^{\circ} \mathrm{C}$ for $10 \mathrm{~min}$. Elution fractions were collected, freeze-dried, diluted in water and loading dye $(6 \times, 225 \mathrm{mM}$ Tris. $\mathrm{HCl}(\mathrm{pH} 6.8), 50 \%$ glycerol, $12.5 \% \beta$-mercaptoethanol, $4.5 \%$ SDS, $0.05 \%$ bromophenol blue), heated for $5 \mathrm{~min}$ to $95^{\circ} \mathrm{C}$ and subjected to SDS-PAGE and western blot analysis using ExtrAvidin ${ }^{\oplus}$-Peroxidase (Sigma-Aldrich).
Control experiments. The control samples were treated as described above. In case of the UV control, the sample was handled in a black Eppendorf tube to exclude UV irradiation. In the beads control water was added instead of the respective PALPs. The control substance (con-1) was applied in the same concentration as the PALPs $(20 \mu \mathrm{M})$. For the competition experiment a 100-fold excess of the competitor (comp-1 or comp-2, respectively, $2 \mathrm{mM}$ ) derivative was incubated with cell lysate for $1 \mathrm{~h}$ on ice before adding the corresponding PALPs.

In-gel digestion. For in-gel digestion each gel lane was cut into small pieces and destained repetitively in acetonitrile/water $(3: 2, \mathrm{v} / \mathrm{v}, 50 \mu \mathrm{L})$ for $30 \mathrm{~min}$ and $\mathrm{NH}_{4} \mathrm{HCO}_{3}(25 \mathrm{mM}, 50 \mu \mathrm{L})$ for $15 \mathrm{~min}$. Then, the gel pieces were incubated with $\mathrm{NH}_{4} \mathrm{HCO}_{3}(20 \mathrm{mM}, 50 \mu \mathrm{L})$ for $15 \mathrm{~min}$. After washing, proteins were reduced with DTT $\left(10 \mathrm{mM}\right.$ in $\left.\mathrm{NH}_{4} \mathrm{HCO}_{3}, 20 \mathrm{mM}, 100 \mu \mathrm{L}\right)$ for $60 \mathrm{~min}$ at $56^{\circ} \mathrm{C}$, followed by alkylation with iodoacetamide $\left(50 \mathrm{mM}\right.$ in $\left.\mathrm{NH}_{4} \mathrm{HCO}_{3}, 20 \mathrm{mM}, 100 \mu \mathrm{L}\right)$ at room temperature for 60 min under protection from UV light. After washing in $\mathrm{NH}_{4} \mathrm{HCO}_{3}(20 \mathrm{mM}, 100 \mu \mathrm{L})$ for $15 \mathrm{~min}$ and in $\mathrm{NH}_{4} \mathrm{HCO}_{3}$ /acetonitrile $(20 \mathrm{mM}, 1: 1$, $\mathrm{v} / \mathrm{v}, 100 \mu \mathrm{L})$ for $10 \mathrm{~min}$ and dehydration in pure acetonitrile $(100 \mu \mathrm{L})$ for $10 \mathrm{~min}$, proteins were digested overnight at $37^{\circ} \mathrm{C}$ with trypsin $(1: 50, \mathrm{w} / \mathrm{w})$ (Promega V5111). Peptides were extracted twice from the gel with acetonitrile/TFA in water $(0.1 \%, 1: 1)$ for $60 \mathrm{~min}$. After desalting using ZipTips (Merck Millipore) the peptides were subjected to mass spectrometric analysis with nano-LC-MS/MS (Proteomics facility, University of Konstanz).

Mass spectrometry. The digests were analysed on a QExactive HF mass spectrometer (Thermo Fisher Scientific, Bremen, Germany) operated with Tune (version 2.9) and interfaced with an Easy-nLC 1200 nanoflow liquid chromatography system (Thermo Fisher Scientific, Bremen, Germany). The peptide digests were reconstituted in $0.1 \%$ formic acid and loaded onto the analytical column $(50 \mu \mathrm{m} \times$ $15 \mathrm{~cm}$ ). Peptides were resolved at a flow rate of $300 \mathrm{~nL} / \mathrm{min}$ using a linear gradient of $6-40 \%$ solvent B ( $0.1 \%$ formic acid in $80 \%$ acetonitrile) over 45 or $60 \mathrm{~min}$. Datadependent acquisition with full scans in a $350-1200 \mathrm{~m} / \mathrm{z}$ range was carried out at a mass resolution of 120,000 . The 20 most intense precursor ions were selected for fragmentation. Peptides with charge states 2-7 were selected and dynamic exclusion was set to $30 \mathrm{~s}$. MS2 scans were carried out at a mass resolution of 15,000. Precursor ions were fragmented using higher-energy collision dissociation (HCD) set to $28 \%$. Each of the three independent biological replicates was measured as technical duplicates.

Data analysis and quantification. Raw files from LC-MS/MS measurements were analyzed using MaxQuant (version 1.6.2.6) with the andromeda search engine with default settings and match between runs and label-free quantification (LFQ) (minimum ratio count 2) enabled ${ }^{26,27}$. For protein identification, the human and the E. coli reference proteome downloaded from the UniProt database (https:// www.uniprot.org/proteomes/) (download date: 02.04.2019 and 01.10.2019) and an integrated database of common contaminants were used. Oxidation, $N$-acetylation, and carbamidomethylation were selected as modifications. Identified proteins were filtered for reverse hits, common contaminants and hits only identified by site at a false discovery rate (FDR) of equal or below 0.01. Further data processing was performed using Perseus software (version 1.6.14.0) ${ }^{28}$. LFQ intensities were $\log _{2}$ transformed. The proteins were filtered to be detected in at least $60 \%$ of the replicate experiments $(n=6)$ and missing values were imputed from a normal distribution (width $=0.3$ and shift $=1.8$ ) in the total matrix mode, based on the assumption that these proteins were below the detection limit. Enriched proteins were identified by a one-way ANOVA-based multiple sample test with $S_{0}$ adjusted to 0.2 , the number of randomizations set to 250 and the permutation-based FDR accepted equal or below 0.01 with technical replicates grouped for randomization. A two-sided Tukey's post hoc test with an accepted FDR value equal or below 0.05 was performed on all ANOVA significant hits. The Tukey's Honest Significant Difference (THSD) performs a pairwise comparison of all conditions and calculates the mean difference between each condition pair. If the difference is greater than or equal to the corresponding THSD, which depends on the number of treatments, the degrees of freedom, the mean squared error and the number of data points in each group, the difference is considered significant. For further analysis only proteins enriched in a PAL experiment against all four corresponding controls were considered. Z-scoring of the median LFQ intensities was performed without grouping and used for unsupervised hierarchical clustering of all significant hits, the distance was set to Euclidian, the linkage to average, and the maximal numbers of clusters to 300 .

GO term and abundance analysis. The obtained protein hits were analyzed using Cytoscape (version 3.8.2) with the BiNGO app (version 3.0.3) to compare the abundance of GO terms in the identified proteins to their frequency in the whole proteome. A one-sided hypergeometric test was performed with a significance level of 0.05 and Benjamini Hochberg False Discovery Rate (FDR) (looks at the frequency with which that GO term appears, the $p$-value consequently falls as the frequency increases ${ }^{50}$. Global frequency is the number of genes annotated to a GO term in the entire background set, while sample frequency is the number of genes annotated to that GO term in the input list. (cf. http://geneontology.org/docs/goenrichment-analysis/). Human and E. coli gene association (.gaf) and ontology files (.obo) were downloaded from geneontology.org (http://geneontology.org) 
(27.01.2020). For the full output of the performed analysis, see Supplementary Data 2 and 4. Human orthologues of the bacterial hits were investigated using PANTHER (version 16.0) ${ }^{42}$ bioinformatics resource.

\section{Biochemical validation experiments}

Expression and purification of human $D c p S^{51}$. The protein expression plasmid pET28b containing the sequence for His-tagged DcpS was kindly provided by A. Rentmeister (Institute of Biochemistry, WWU Münster). After transformation into BL21 (DE3) E. coli cells, the cells were grown in LB medium containing $100 \mathrm{mg} / \mathrm{L}$ kanamycin at $37^{\circ} \mathrm{C}$ overnight. The pre-culture was diluted with medium containing $100 \mathrm{mg} / \mathrm{L}$ kanamycin to an $\mathrm{OD}_{600}$ value of 0.1 . Cells were grown at $37^{\circ} \mathrm{C}$ until they reached an $\mathrm{OD}_{600}$ of approximately 1.1. Protein expression was induced by addition of $1 \mathrm{mM} \mathrm{IPTG}$ at $25^{\circ} \mathrm{C}$ for $4 \mathrm{~h}$. Then, cells were pelleted, resuspended in lysis buffer ( $50 \mathrm{mM}$ Tris. $\mathrm{HCl}(\mathrm{pH} 8.0), 350 \mathrm{mM} \mathrm{NaCl}, 20 \%$ sucrose, $20 \mathrm{mM}$ imidazole, $1 \mathrm{mM} \beta$-mercaptoethanol) and lysed by sonication at an amplitude of $20 \%$ for $45 \mathrm{~s}$, five times. The lysate was clarified by high speed centrifugation and purified by immobilized metal ion affinity chromatography (IMAC) using a His$\mathrm{Trap}^{\mathrm{TM}} \mathrm{FF}$ crude column on an ÄKTA system. The protein was eluted in lysis buffer, with linear increasing concentrations of imidazole (12.5-250 mM). The pooled fractions were further purified by size exclusion chromatography (Sephadex G-25) using $10 \mathrm{mM}$ Tris. $\mathrm{HCl}$ (pH 8.0), $25 \mathrm{mM} \mathrm{NaCl}, 1 \mathrm{mM}$ DTT as mobile phase. Protein purity was analyzed by $12.5 \%$ SDS-PAGE followed by Coomassie blue staining, and the concentration was determined by UV absorption (Nanodrop ND1000 , Peqlab). The protein was stored at $-80^{\circ} \mathrm{C}$ until use.

Investigation of $m^{7} G p_{3} G$ cleavage by $D c p S$ in the presence of $A p_{3} A$ and $A p_{4} A . A p_{3} A$ and $\mathrm{Ap}_{4} \mathrm{~A}$ (Jena Bioscience) were diluted in DcpS assay buffer (10 mM Tris. $\mathrm{HCl}$ (pH 7.5), $200 \mathrm{mM} \mathrm{KCl}, 0.5 \mathrm{mM}$ EDTA, $1.0 \mathrm{mM} \mathrm{DTT})^{52}$ to a final concentration of $200 \mu \mathrm{M}$ in $150 \mu \mathrm{L}$. DcpS was added and the mixture was incubated at $30^{\circ} \mathrm{C}$ for $15 \mathrm{~min}$. The cap analog was added and the mixture was incubated for up to $1 \mathrm{~h}$. Aliquots were taken at the indicated time points and the enzymatic reaction was stopped by denaturing DcpS for $2.5 \mathrm{~min}$ at $97^{\circ} \mathrm{C} .7 \mu \mathrm{L}$ of $10 \%$ TFA were added, as well as $1 \mu \mathrm{L}$ of a $1 \mathrm{mM}$ adenosine solution as internal standard. The protein was removed with U-C18 ZipTips (Merck Millipore), the mixture was freeze dried and then dissolved in water for analysis by RP-HPLC using a Pyramid column. Samples without $\mathrm{Ap}_{3} \mathrm{~A}$ or $\mathrm{Ap}_{4} \mathrm{~A}$ were treated the same way. All experiments were performed three times as biological replicates. Peak areas were determined using LabSolutions Shimadzu (version 5.71) and normalized by the adenosine peak. Peak areas for the cleavage product (GDP) were compared using GraphPad PRIMS (version 6.01) and all new peaks were collected and further characterized by ESI-MS.

E2 charging assay. Human N-terminal His-tagged ubiquitin-like modifier activating enzyme 1 (UBA1) was expressed in $E$. coli BL21 RIL and purified via IMAC and size exclusion chromatography ${ }^{53}$. The C-terminally His-tagged E2 enzyme UbcH7 was expressed in E. coli BL21 (DE3) and purified via IMAC ${ }^{5}$. Ub was expressed in E. coli BL21 (DE3) and purified via IMAC and cation exchange chromatography ${ }^{7}$.

The E2 charging assay was performed with $250 \mathrm{nM}$ UBA1, $4 \mu \mathrm{M} \mathrm{UbcH7}, 15 \mu \mathrm{M}$ Ub, $25 \mathrm{mM}$ Tris. $\mathrm{HCl}$ (pH 7.5), $50 \mathrm{mM} \mathrm{NaCl}, 0.1 \mathrm{mM} \mathrm{DTT}, 10 \mathrm{mM} \mathrm{MgCl}_{2}$, and started with $0.2 \mathrm{mM}$ of the indicated nucleotide (ATP, $\mathrm{Ap}_{3} \mathrm{~A}$, or $\mathrm{Ap}_{4} \mathrm{~A}$ ). For the SAP control, the nucleotides were pre-incubated with 0.5 units of shrimp alkaline phosphatase (rSAP) (New England Biolabs) at $37^{\circ} \mathrm{C}$ for $30 \mathrm{~min}$, followed by inactivation of the rSAP at $65^{\circ} \mathrm{C}$ for $15 \mathrm{~min}$. The reaction mixtures were incubated at $20^{\circ} \mathrm{C}$ and enzymatic reactions were stopped at the indicated time points by the addition of $6 \times$ non-reducing SDS loading dye. To the DTT controls $1 \mu \mathrm{L}$ of $1 \mathrm{M}$ DTT was added before stopping the reaction. Samples were separated by $15 \%$ SDSPAGE gels and stained with Coomassie blue.

Expression and purification of human LDHA. The codon optimized cDNA of human LDHA (Thermo Fisher Scientific) was cloned into the pET21a vector using NdeI and XhoI restriction sites to generate pET21a-LDHA. The plasmid was transformed into BL21 (DE3) E. coli cells, which were then grown in LB medium containing $100 \mathrm{mg} / \mathrm{L}$ carbenicillin at $37^{\circ} \mathrm{C}$ overnight. The pre-culture was diluted with $\mathrm{LB}$ medium containing $100 \mathrm{mg} / \mathrm{L}$ carbenicillin to an $\mathrm{OD}_{600}$ value of 0.1 . Cells were grown at $37^{\circ} \mathrm{C}$ until they reached an $\mathrm{OD}_{600}$ of approximately 0.6. Protein expression was induced by addition of $1 \mathrm{mM}$ IPTG at $25^{\circ} \mathrm{C}$ for $4 \mathrm{~h}$. Then, cells were pelleted, resuspended in lysis buffer (20 mM HEPES (pH 7.5), $200 \mathrm{mM} \mathrm{NaCl}$, $1 \mathrm{mM} \beta$-mercaptoethanol, $1 \%$ Triton $^{\mathrm{ms}} \mathrm{X}-100,0.1 \mathrm{M}$ Pefabloc, $1 \mu \mathrm{g} / \mathrm{mL}$ aprotinin/ leupeptin) and lysed by sonication at an amplitude of $20 \%$ for $30 \mathrm{~s}$, three times. The lysate was clarified by high speed centrifugation and purified by immobilized metal ion affinity chromatography (IMAC) using a HisTrap ${ }^{\mathrm{TM}} \mathrm{FF}$ crude column $(1 \mathrm{~mL}$, GE Healthcare) on an ÄKTA system. The protein was eluted in $20 \mathrm{mM}$ HEPES (pH 7.5), $200 \mathrm{mM} \mathrm{NaCl}, 1 \mathrm{mM} \beta$-mercaptoethanol, with linear increasing concentrations of imidazole $(30-500 \mathrm{mM})$. Fractions containing pure LDHA protein were identified by $12.5 \%$ SDS-PAGE followed by Coomassie blue staining and pooled. The elution buffer was replaced by LDHA storage buffer (20 mM HEPES ( $\mathrm{pH} 7.5)$, $200 \mathrm{mM} \mathrm{NaCl}, 10 \%$ glycerol) via dialysis overnight. The protein concentration was determined by BCA assay (Kit, Thermo Fisher Scientific). The protein was stored at $-20^{\circ} \mathrm{C}$ until use.
Expression and purification of human PGK1. The codon optimized cDNA of human PGK1 (Thermo Fisher Scientific) was cloned into the pET21a vector using NdeI and XhoI restriction sites to generate pET21a-PGK1. The plasmid was transformed into BL21 (DE3) E. coli cells, which were then grown in LB medium containing $100 \mathrm{mg} / \mathrm{L}$ carbenicillin at $37^{\circ} \mathrm{C}$ overnight. The pre-culture was diluted with $\mathrm{LB}$ medium containing $100 \mathrm{mg} / \mathrm{L}$ carbenicillin to an $\mathrm{OD}_{600}$ value of 0.1 . Cells were grown at $37^{\circ} \mathrm{C}$ until they reached an $\mathrm{OD}_{600}$ of approximately 0.6. Protein expression was induced by addition of $1 \mathrm{mM}$ IPTG at $25^{\circ} \mathrm{C}$ for $5 \mathrm{~h}$. Then, cells were pelleted, resuspended in lysis buffer ( $50 \mathrm{~mm}$ Tris $\cdot \mathrm{HCl}(\mathrm{pH} 8.0), 150 \mathrm{mM}$ $\mathrm{NaCl}, 1 \mathrm{mM}$ DTT, $1 \%$ Triton $^{\mathrm{mm}} \mathrm{X}-100,0.1 \mathrm{M}$ Pefabloc, $1 \mu \mathrm{g} / \mathrm{mL}$ aprotinin/leupeptin) and lysed by sonication at an amplitude of $20 \%$ for $30 \mathrm{~s}$, three times. The lysate was clarified by high speed centrifugation and purified by immobilized metal ion affinity chromatography (IMAC) using a HisTrap ${ }^{\mathrm{TM}}$-FF column $(1 \mathrm{~mL}$ GE Healthcare) on an ÄKTA system. The protein was eluted in $50 \mathrm{mM}$ Tris. $\mathrm{HCl}$ (pH 8.0) and $150 \mathrm{mM} \mathrm{NaCl}$, with linear increasing concentrations of imidazole (30-500 mm). Fractions containing pure PGK1 protein were identified by $12.5 \%$ SDS-PAGE followed by Coomassie blue staining and pooled. The elution buffer was replaced by PGK1 storage buffer (50 mM Tris. $\mathrm{HCl}(\mathrm{pH} 8.0), 150 \mathrm{mM} \mathrm{NaCl}$, $1 \mathrm{mM}$ DTT, $10 \%$ glycerol) via dialysis overnight. The protein concentration was determined by BCA assay (Kit, Thermo Fisher Scientific). The protein was stored at $-80{ }^{\circ} \mathrm{C}$ until use.

Determination of binding affinities by fluorescence polarization. Prior to the experiments the protein storage buffers were replaced by the respective fluorescence polarization assay buffers for LDHA (20 mM HEPES (pH 7.5), $200 \mathrm{mM}$ $\mathrm{NaCl}, 0.01 \%$ Triton $\left.^{\text {nt }} \mathrm{X}-100\right)$ and PGK1 (20 mM Tris. $\mathrm{HCl}$ (pH 7.5), $1 \mathrm{mM}$ DTT, $5 \mathrm{mM} \mathrm{MgCl}_{2}, 0.01 \%$ Triton $^{\mathrm{st}} \mathrm{X}-100$. The protein concentrations were determined by $\mathrm{BCA}$ assays and protein dilution series using the same buffers were prepared. $\mathrm{C} 2$-(5-FAM)- $\mathrm{Ap}_{3} \mathrm{~A}\left(\mathrm{~F}-\mathrm{Ap}_{3} \mathrm{~A}\right)$ was added to the protein samples, yielding reaction mixtures containing $25 \mathrm{nM} \mathrm{F}-\mathrm{Ap}_{3} \mathrm{~A}$ and varying protein concentrations (as noted) in an overall volume of $110 \mu \mathrm{L}$. For each reaction mixture $30 \mu \mathrm{L}$ were transferred to black 384-well non-binding microplates no. 781900 (Greiner Bio-One) in three separate wells. Samples were centrifuged $\left(200 \times g, 2 \mathrm{~min}, 4^{\circ} \mathrm{C}\right)$ and incubated on ice for $15 \mathrm{~min}$ followed by $30 \mathrm{~min}$ incubation at $30^{\circ} \mathrm{C}$. FP measurements were subsequently recorded on a Tecan infinite 500 plate reader. Emission was measured at $535 \mathrm{~nm}$ with two filters transmissive for polarized light, either parallel or perpendicular to the plane of excitation. The FP values were directly provided as millipolarization (mP). To correct for instrument intrinsic differences of the sensitivity towards detecting parallelly and perpendicularly emitted polarized light, the G-factor was determined and used for subsequent measurements. For this calibration, the FP value of a $1 \mathrm{nM} 5$-FAM solution in $0.01 \mathrm{M} \mathrm{NaOH}$ was measured and set to $20 \mathrm{mP}$. The mean and the standard deviation were calculated for each sample. The binding curves were corrected by subtracting the background FP value. Data was analyzed with GraphPad PRISM (version 6.01) and curve fittings were calculated by using the equation for one site specific binding $\left(K_{\mathrm{D}}\right)$ with the maximum specific binding $B_{\max }$ and the equilibrium constant $K_{\mathrm{D}}$. The obtained binding parameters are shown in Supplementary Table 1.

Statistic and reproducibility. The stability of $\mathrm{Ap}_{3} \mathrm{~A}$ and $\mathrm{Ap}_{4} \mathrm{~A}$ in human cell lysates was monitored twice with comparable results. Determination of $\mathrm{Ap}_{3} \mathrm{~A}$ and $\mathrm{Ap}_{4} \mathrm{~A}$ levels were performed in 15 biological replicates for each condition. Samples were measured in technical duplicates and averaged. Measurements with a signal to noise ratio below 7 were excluded. All PAL experiments were performed in biological triplicates. Western blot analysis of isolated proteins was performed for each replicate with comparable results. After digestion of the proteins, nano-LC-MS/MS was measured for each replicate in technical duplicates. The cleavage reaction of $\mathrm{m}^{7} \mathrm{Gp}_{3} \mathrm{G}$ by DcpS was performed in biological triplicates. The transthioesterification was performed twice as biological replicates with matching results. All FP measurements were performed in technical triplicates. For details of statistical analysis see respective methods section and figure legends.

\section{Data availability}

The data that support this study are available from the corresponding authors upon reasonable request. The mass spectrometry proteomics data generated in this study have been deposited in the ProteomeXchange Consortium via the PRIDE partner repository ${ }^{55}$ under accession code PXD020740. Figures with associated raw data: Figs. 2-7 and Supplementary Figs. 1, 6, 7, 9 and 10. Source data are provided with this paper. For protein identification, the human and the E. coli reference proteome downloaded from the UniProt database (https://www.uniprot.org/proteomes/) (download date: 02.04.2019 and 01.10 .2019 ) and an integrated database of common contaminants were used. For GO term analysis Human and E. coli gene association (.gaf) and ontology files (.obo) were downloaded from geneontology.org (http://geneontology.org) (27.01.2020). Source data are provided with this paper.

Received: 17 August 2020; Accepted: 10 September 2021; Published online: 04 October 2021 


\section{References}

1. Finamore, F. \& Warner, A. The occurrence of P1, P4-diguanosine 5' tetraphosphate in brine shrimp eggs. J. Biol. Chem. 238, 344-348 (1963).

2. McLennan, A. G. Dinucleoside polyphosphates-friend or foe? Pharmacol. Ther. 87, 73-89 (2000).

3. McLennan, A. G. Ap4A and other Dinucleoside Polyphosphates. (CRC Press, 1992).

4. Bochner, B. R., Lee, P. C., Wilson, S. W., Cutler, C. W. \& Ames, B. N. AppppA and related adenylylated nucleotides are synthesized as a consequence of oxidation stress. Cell 37, 225-232 (1984).

5. Johnstone, D. B. \& Farr, S. B. AppppA binds to several proteins in Escherichia coli, including the heat shock and oxidative stress proteins DnaK, GroEL, E89, C45 and C40. EMBO J. 10, 3897-3904 (1991).

6. Fraga, H. \& Fontes, R. Enzymatic synthesis of mono and dinucleoside polyphosphates. BBA-Gen. Subj. 1810, 1195-1204 (2011).

7. Götz, K. H. et al. Formation of the alarmones diadenosine triphosphate and tetraphosphate by ubiquitin- and ubiquitin-like-activating enzymes. Cell Chem. Biol. 26, 1535-1543.e1535 (2019).

8. Barnes, L. D. et al. Fhit, a putative tumor suppressor in humans, is a dinucleoside $5^{\prime}, 5^{\prime \prime \prime}$-P1,P3-triphosphate hydrolase. Biochemistry $\mathbf{3 5}$, 11529-11535 (1996).

9. McLennan, A. G. The MutT motif family of nucleotide phosphohydrolases in man and human pathogens (review). Int. J. Mol. Med. 4, 79-168 (1999).

10. Saldivar, J. C., Shibata, H. \& Huebner, K. Pathology and biology associated with the fragile FHIT gene and gene product. J. Cell. Biochem. 109, 858-865 (2010).

11. Oka, K. et al. Nudix-type motif 2 in human breast carcinoma: a potent prognostic factor associated with cell proliferation. Int. J. Cancer128, 1770-1782 (2011).

12. Marriott, A. S. et al. NUDT2 disruption elevates diadenosine tetraphosphate (Ap $4 \mathrm{~A}$ ) and down-regulates immune response and cancer promotion genes. PLoS ONE 11, e0154674 (2016).

13. Blackburn, G. M., Liu, X., Rösler, A. \& Brenner, C. Two hydrolase resistant analogues of diadenosine $5^{\prime}, 5^{\prime \prime \prime}-\mathrm{P}, \mathrm{P}$-triphosphate for studies with FHIT, the human fragile histidine triad protein. Nucleosides Nucleotides 17, 301-308 (1998).

14. Fischer, B. et al. 2-thioether 5'-O-(1-thiotriphosphate) adenosine derivatives as new insulin secretagogues acting through P2Y-receptors. J. Med. Chem. 42, 3636-3646 (1999).

15. Kalek, M., Jemielity, J., Stepinski, J., Stolarski, R. \& Darzynkiewicz, E. A direct method for the synthesis of nucleoside $5^{\prime}$-methylenebis(phosphonate)s from nucleosides. Tetrahedron Lett. 46, 2417-2421 (2005).

16. Hacker, S. M. et al. Fingerprinting differential active site constraints of ATPases. Chem. Sci. 4, 1588-1596 (2013).

17. Hacker, S. M. et al. Fluorogenic ATP analogues for online monitoring of ATP consumption: observing ubiquitin activation in real time. Angew. Chem. Int. Ed. 52, 11916-11919 (2013).

18. Hacker, S. M., Mortensen, F., Scheffner, M. \& Marx, A. Selective monitoring of the enzymatic activity of the tumor suppressor Fhit. Angew. Chem. Int. Ed. 53, 10247-10250 (2014).

19. Halloran, M. W. \& Lumb, J. P. Recent applications of diazirines in chemical proteomics. Chemistry 25, 4885 (2019).

20. Dubinsky, L., Krom, B. P. \& Meijler, M. M. Diazirine based photoaffinity labeling. Biorg. Med. Chem. 20, 554 (2012).

21. Hirsch, J. D. et al. Easily reversible desthiobiotin binding to streptavidin, avidin, and other biotin-binding proteins: uses for protein labeling, detection, and isolation. Anal. Biochem. 308, 343-357 (2002)

22. Joachimiak, Ł. \& Błażewska, K. M. Phosphorus-based probes as molecular tools for proteome studies: recent advances in probe development and applications. J. Med. Chem. 308, 343-357 (2018).

23. Yanachkov, I. B., Dix, E. J., Yanachkova, M. I. \& Wright, G. E. P1,P2Diimidazolyl derivatives of pyrophosphate and bis-phosphonates-synthesis, properties, and use in preparation of dinucleoside tetraphosphates and analogs. Org. Biomol. Chem. 9, 730-738 (2011).

24. Michael Blackburn, G., Guo, M.-J., Langston, S. P. \& Taylor, G. E. Novel phosphonate and thiophosphate analogues of Ap3A, diadenosine $5^{\prime}, 5^{\prime \prime \prime}-\mathrm{P} 1, \mathrm{P} 3$ triphosphate. Tetrahedron Lett. 31, 5637-5640 (1990).

25. Fisher, D. I. \& McLennan, A. G. Correlation of intracellular diadenosine triphosphate (Ap3A) with apoptosis in Fhit-positive HEK293 cells. Cancer Lett. 259, 186-191 (2008).

26. Cox, J. et al. Accurate proteome-wide label-free quantification by delayed normalization and maximal peptide ratio extraction, termed MaxLFQ. Mol. Cell. Proteom. 13, 2513-2526 (2014).

27. Cox, J. \& Mann, M. MaxQuant enables high peptide identification rates, individualized p.p.b.-range mass accuracies and proteome-wide protein quantification. Nat. Biotechnol. 26, 1367 (2008).

28. Tyanova, S. et al. The Perseus computational platform for comprehensive analysis of (prote)omics data. Nat. Methods 13, 731 (2016).
29. Wallrodt, S., Buntz, A., Wang, Y., Zumbusch, A. \& Marx, A. Bioorthogonally functionalized NAD + analogues for in-cell visualization of poly(ADP-Ribose) formation. Angew. Chem. Int. Ed. 55, 7660-7664 (2016).

30. Wang, Y., Rösner, D., Grzywa, M. \& Marx, A. Chain-terminating and clickable NAD + analogues for labeling the target proteins of ADPribosyltransferases. Angew. Chem. Int. Ed. 53, 8159-8162 (2014).

31. Zamecnik, P. G., Stephenson, M. L., Janeway, C. M. \& Randerath, K. Enzymatic synthesis of diadenosine tetraphosphate and diadenosine triphosphate with a purified lysyl-sRNA synthetase. Biochem. Biophys. Res. Commun. 24, 91-97 (1966)

32. Despotovic, D. et al. Diadenosine tetraphosphate (Ap4A) - an E. coli alarmone or a damage metabolite? FEBS J. 284, 2194-2215 (2017).

33. Fernández-Justel, D., Peláez, R., Revuelta, J. L. \& Buey, R. M. The Bateman domain of IMP dehydrogenase is a binding target for dinucleoside polyphosphates. J. Biol. Chem. 294, 14768-14775 (2019).

34. Maere, S., Heymans, K. \& Kuiper, M. BiNGO: a cytoscape plugin to assess overrepresentation of Gene Ontology categories in biological networks. J. Bioinform. 21, 3448-3449 (2005).

35. Wang, Z. \& Kiledjian, M. Functional link between the mammalian exosome and mRNA decapping. Cell 107, 751-762 (2001).

36. Liu, H., Rodgers, N. D., Jiao, X. \& Kiledjian, M. The scavenger mRNA decapping enzyme DcpS is a member of the HIT family of pyrophosphatases. EMBO J. 21, 4699-4708 (2002).

37. Groen, E. J. N. \& Gillingwater, T. H. UBA1: at the crossroads of ubiquitin homeostasis and neurodegeneration. Trends Mol. Med. 21, 622-632 (2015).

38. Huangyang, P. \& Simon, M. C. Hidden features: exploring the non-canonival functions of metabolic enzymes. Dis. Models Mech. 11, dmm033365 (2018).

39. Yu, X. \& Li, S. Non-metabolic functions of glycolytic enzymes in tumorigenesis. Oncogene 36, 2629 (2017).

40. Hall, M. D. et al. Fluorescence polarization assays in high-throughput screening and drug discovery: a review. Methods Appl. Fluores. 4, 022001 (2016).

41. Rossi, A. M. \& Taylor, C. W. Analysis of protein-ligand interactions by fluorescence polarization. Nat. Protoc. 6, 365 (2011)

42. Mi, H., Muruganujan, A., Ebert, D., Huang, X. \& Thomas, P. D. PANTHER version 14: more genomes, a new PANTHER GO-slim and improvements in enrichment analysis tools. Nucleic Acids Res. 47, D419-D426 (2018).

43. Guo, W. et al. Isolation and identification of diadenosine $5^{\prime}, 5^{\prime \prime \prime}-\mathrm{P} 1, \mathrm{P}$ 4-tetraphosphate binding proteins using magnetic bio-panning. Bioorg. Med. Chem. Lett. 21, 7175-7179 (2011)

44. Azhar, M. A., Wright, M., Kamal, A., Nagy, J. \& Miller, A. D. Biotin-c10$\mathrm{AppCH} 2 \mathrm{ppA}$ is an effective new chemical proteomics probe for diadenosine polyphosphate binding proteins. Bioorg. Med. Chem. Lett. 24, 2928-2933 (2014).

45. Sobotta, M. C. et al. Exposing cells to $\mathrm{H}_{2} \mathrm{O}_{2}$ : a quantitative comparison between continuous low-dose and one-time high-dose treatments. Free Radic. Biol. Med. 60, 325-335 (2013).

46. Baker, J. C. \& Jacobson, M. K. Alteration of adenyl dinucleotide metabolism by environmental stress. Proc. Natl. Acad. Sci. USA. 83, 2350-2352 (1986).

47. Marriott, A. S. et al. Diadenosine $5^{\prime}, 5^{\prime \prime \prime}-\mathrm{P} 1, \mathrm{P} 4$-tetraphosphate (Ap4A) is synthesized in response to DNA damage and inhibits the initiation of DNA replication. DNA Repair 33, 90-100 (2015).

48. Luciano, D. J. \& Belasco, J. G. $\mathrm{Np}_{4} \mathrm{~A}$ alarmones function in bacteria as precursors to RNA caps. PNAS 117, 4445-4446 (2020).

49. Hudeček, O. et al. Dinucleoside polyphosphates act as $5^{\prime}$-RNA caps in bacteria. Nat. Commun. 11, 1052 (2020).

50. Koh, G. C. K. W. et al. Analyzing protein-protein interaction networks. J. Proteome Res. 11, 2014-2031 (2012).

51. $\mathrm{Gu}, \mathrm{M}$. et al. Insights into the structure, mechanism, and regulation of scavenger mRNA decapping activity. Mol. Cell 14, 67-80 (2004).

52. Kasprzyk, R. et al. Acetylpyrene-labelled 7-methylguanine nucleotides: unusual fluorescence properties and application to decapping scavenger activity monitoring. Org. Biomol. Chem. 14, 3863-3868 (2016)

53. Berndsen, C. E. \& Wolberger, C. A spectrophotometric assay for conjugation of ubiquitin and ubiquitin-like proteins. Anal. Biochem. 418, 102-110 (2011)

54. Mortensen, F. et al. Role of ubiquitin and the HPV E6 oncoprotein in E6AP mediated ubiquitination. PNAS 112, 9872-9877 (2015).

55. Vizcaíno, J. A. et al. The PRoteomics IDEntifications (PRIDE) database and associated tools: status in 2013. Nucleic Acids Res. 41, D1063-D1069 (2012).

\section{Acknowledgements}

The authors thank A. Rentmeister (University of Münster) for providing the DcpS plasmid construct and A. Marquardt (Proteomics facility, University of Konstanz) for performing the LC-MS/MS measurements. F.S. is grateful for funding from the German Research Foundation Emmy Noether Programme to F.S. (STE 2517/1-1). A.M. acknowledges support from the German Research Foundation (DFG grant MA 2288/19) 


\section{Author contributions}

A.M., L.K., C.J.A. designed and L.K., C.J.A., H.K.S., F.M.S., Y.Y., and J.W. performed the experiments and L.K., C.J.A., M.L.N., and F.S. analyzed the data. A.M., L.K., and C.J.A. wrote the manuscript. K.S. and M.S. provided UBA1 and UbcH7 and assisted with these experiments and edited the manuscript.

\section{Funding}

Open Access funding enabled and organized by Projekt DEAL.

\section{Competing interests}

The authors declare no competing interests.

\section{Additional information}

Supplementary information The online version contains supplementary material available at https://doi.org/10.1038/s41467-021-26075-4.

Correspondence and requests for materials should be addressed to Andreas Marx.

Peer review information Nature Communications thanks H. Christian Eberl and the other, anonymous, reviewer(s) for their contribution to the peer review of this work.
Reprints and permission information is available at http://www.nature.com/reprints

Publisher's note Springer Nature remains neutral with regard to jurisdictional claims in published maps and institutional affiliations.

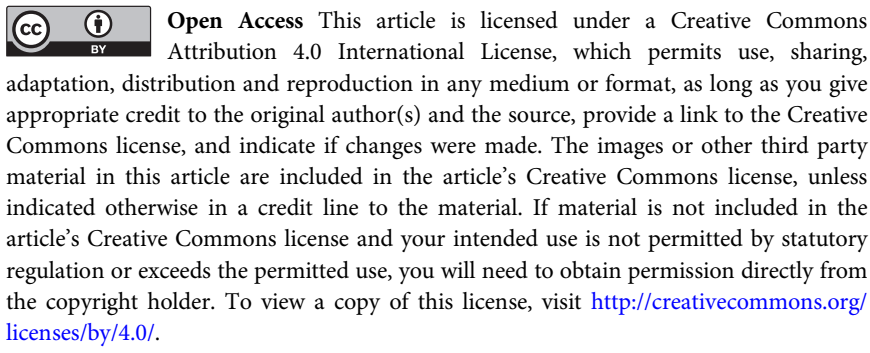

(C) The Author(s) 2021 